\title{
Gender and socioeconomic inequalities in health and wellbeing across age in France and Switzerland
}

\author{
Anna Barbuscia ${ }^{1,2, *}$ and Chiara Comolli ${ }^{2}$
}

\begin{abstract}
There is increasing evidence that wellbeing is unequally distributed across sociodemographic groups in contemporary societies. However, less is known about the divergence across social groups of trajectories of wellbeing across age groups. This issue is of great relevance in contexts characterised by changing population structures and growing imbalances across and within generations, and in which ensuring that everyone has the opportunity to have a happy and healthy life course is a primary welfare goal. In this study, we investigate wellbeing trends in France and Switzerland across age, gender, and socioeconomic status groups. We use two household surveys (the Santé et Itinéraires Professionnels and the Swiss Household Panel) to compare the unfolding inequalities in health and wellbeing across age groups in two rich countries. We view wellbeing as multidimensional, following the literature highlighting the importance of considering different dimensions and measures of wellbeing. Thus, we investigate a number of outcomes, including different measures of physical and mental health, as well as of relational wellbeing, using a linear regression model and a linear probability model. Our findings show interesting country and dimension-specific heterogeneities in the development of health and wellbeing over age. While our results indicate that there are gender and educational inequalities in both Switzerland and France, and that gender inequalities in mental health accumulate with age in both countries, we also find that educational inequalities in health and wellbeing remain rather stable across age groups.
\end{abstract}

Keywords: multidimensional wellbeing; sociodemographic inequalities; age development; cross-country comparison

\footnotetext{
${ }^{1}$ INED, Paris, France

${ }^{2}$ University of Lausanne, Switzerland

*Correspondence to: Anna Barbuscia, anna.barbuscia@ined.fr
} 


\section{Introduction}

In contexts characterised by changing population structures and growing imbalances across and within generations and social groups, ensuring a high quality of life and a healthy life course development for everyone becomes a paramount welfare objective. Despite the abundant literature on health and wellbeing, how these indicators vary with age remains the subject of theoretical and empirical debates. While there is consistent evidence that physical health tends to worsen with age, patterns of mental health and subjective wellbeing are less clear, with a majority of studies showing that both might actually be lower among mid-age groups (Lang et al. 2011; Blanchflower and Oswald 2016). However, other studies have reported that wellbeing increases with age (Walker 2005; Frijters and Beatton 2012), even though physical health worsens, or that levels of wellbeing do not change at all across age groups (De Neve et al. 2012). The few studies that have considered domain-specific satisfaction have tended to show that age trajectories of satisfaction diverge considerably across domains (McAdams et al. 2012; Easterlin 2006).

In parallel, a growing number of studies in the fields of economics, psychology, sociology and gerontology have focused on how wellbeing is (unequally) distributed across sociodemographic groups in contemporary societies, and have shown that inequalities are increasingly being observed in a number of countries (Mackenbach 2012; Townsend and Davidson 1982; Elo 2009). A rich literature on health inequalities using different measures of both self-reported and objective health has reported that individuals with higher incomes and educational levels tend to experience better health over their life course (e.g., Mackenbach et al. 1997; Marmot 2005), albeit with important differences across countries (Kunst et al. 1995). While there are indications that gender differences in overall health might be smaller than was previously thought (Arber and Cooper 1999; Oksuzyan et al. 2019), women generally report having lower levels of physical and mental health than men (Crimmins and Saito 2001; Dahlin and Härkönen 2013; Lee et al. 2016). It also appears that subjective wellbeing is heterogeneously distributed across social groups. There is, for example, extensive evidence that higher education tends to be associated with greater happiness, as well as with better health. However, findings on gender differences in life satisfaction have been more contradictory, with some studies showing that women tend to be happier than men (Blanchflower and Oswald 2004; Easterlin 2001), and others reaching the opposite conclusion (Pinquart and Sörensen 2001).

Moreover, even less is known about the divergence of age trajectories of health and wellbeing across those social groups. According to the cumulative disadvantage theory, early inequalities may be exacerbated by the ageing process, causing wellbeing trajectories to diverge over the life course (Dannefer 2003). Well-educated individuals are less likely to face risky situations and are less vulnerable when they experience adverse life course events such as job loss, illness, or financial strain. Educational achievement equips individuals with positive attitudes that are useful for the maintenance of health across the life course. Furthermore, being employed 
favours social integration, and can increase an individual's social support and opportunities (Loscocco and Spitze 1990; Cerci and Dumludag 2019). By contrast, the age-as-leveller hypothesis argues that the ageing process could smooth initial differences across groups if the resources that generated the inequality in the first place become less useful over the life course (Lynch 2003). In addition, the survival selection process means that the happier and healthier individuals in each group live longer, and thus participate in surveys longer (Ulloa et al. 2013; Kratz and Patzina 2020). This implies that the group of survivors at older ages are more homogenous. The empirical findings reflect this theoretical duality: some studies have found that gender and educational gaps widen with age (Pinquart and Sörensen 2001), while others have reported constant or shrinking inequalities (Yang 2008).

Finally, a number of studies have highlighted the importance of broadly interpreting the concept of wellbeing as being composed of a number of factors (Pollard and Lee 2003; Cronin de Chavez et al. 2005; Huppert 2013; Infurna and Luthar 2017). A satisfactory ageing process entails not just having high levels of subjective, psychological, relational, and financial wellbeing; but also remaining in good health. A number of investigations have compared multidimensional measures with standard satisfaction questions, and most found only small or moderate correlations (e.g., Huppert and So 2013; Ryff and Keyes 1995). Thus, measurements of wellbeing may not be reducible to a simple, unidimensional notion such as life satisfaction without losing a great deal of potentially valuable information (Keyes 2007). However, most of the work on wellbeing has been undertaken within single disciplines, and has tended to focus on one aspect of the concept, rather than on drawing together the physical, psychological and socioeconomic aspects of wellbeing (Cronin de Chavez et al. 2005).

In this study, we contribute to the literature on unequal age trends in health and wellbeing across gender and socioeconomic status by illustrating how these trends unfold in two different contexts using data from France and Switzerland. While both of these European countries are considered conservative welfare states (Esping-Andersen 1990), they differ in a number of aspects that shape inequalities in sociodemographic health and wellbeing. First, compared to the French welfare state, the Swiss welfare state shares many more features with the liberal welfare system, especially in terms of its privatised health care system. Second, gender norms and the related family and labour market institutions tend to be much more traditional and oriented towards the male breadwinner model (and towards greater financial insecurity among women) in Switzerland than in France. Interesting differences in the health and wellbeing profiles of the two countries can be observed, which provide us with important insights into the cultural and institutional differences in their determinants, and again highlight the importance of considering the multiple dimensions of quality of life (Huppert et al. 2009). Because the questions on health and wellbeing in the two surveys used here were formulated in different ways, we cannot make direct cross-country comparisons. However, exploring the unfolding of health and wellbeing inequalities across age groups in two different contexts may 
enable us to identify the circumstances that are associated with growing or shrinking inequalities within countries (Kunst et al. 1995).

We use data from the 2006 waves of the Santé et intineraire professionnel (SIP) for France and the Swiss Household Panel (SHP) for Switzerland to study individuals of working ages. The two surveys provide a variety of indicators of health and wellbeing, as well as demographic and socioeconomic variables. We focus on four dimensions of physical and mental health and two domain-specific wellbeing measures: relational and professional wellbeing. Our study is descriptive in nature. Our main aim is to explore the gender and educational inequalities in the age trends in two different contexts, while focusing on less investigated indicators of health and wellbeing. We contribute to - and hope to partially reconcile - the streams of literature on the age-wellbeing nexus, the unfolding of wellbeing inequalities over the life course, and the contextual determinants of those age trends and heterogeneities.

\section{Background}

\subsection{The social stratification of health and wellbeing across age}

Sociology and social stratification studies have documented that wellbeing is unequally distributed across demographic and socioeconomic groups (Mackenbach 2012; Townsend and Davidson 1982; Elo 2009). In particular, health and wellbeing appear to differ between women and men. Although women are consistently found to have higher life expectancy than men, net of age, men seem to fare better than women with respect to objective and subjective measures of health. On average, women report lower self-rated health and a higher prevalence of mental health issues (e.g., depression and sleep disorders) than men (Crimmins and Saito 2001; Dahlin and Härkönen 2013; Lee et al. 2016; Troxel et al. 2010). Interestingly, men and women tend to diverge in terms of the types of mental and physical illnesses they have (Needham and Hill 2010). Moreover, the results on gender differences in subjective wellbeing are not consistent. Some studies have shown that women are (slightly) happier than men (Arrosa and Gandelman 2016), while others have found that men are happier and more satisfied with life at all ages (Pinquart and Sörensen 2001).

The positive association between higher education and both subjective wellbeing and physical and mental health is well established (Lleras-Muney 2005; Blanchflower and Oswald 2004; Easterlin 2001; Subramanian et al. 2005). Because having formal education develops people's competences on many levels, it increases their ability and motivation to control and shape their lives (Mirowsky and Ross 1998, 2007; Wheaton 1980). Having higher levels of education, human capital, selfesteem and self-efficacy directly increases people's emotional wellbeing by enabling them to develop emotional resilience and the ability to cope with adversity and 
stress. A person who has a strong sense of control over her life tends to have lower levels of physical and psychological distress, although her level of dissatisfaction with life may not be lower ${ }^{1}$ (Ross and Van Willigen 1997; Edgerton et al. 2012; Hale 2005). Other factors linking formal education to health are having a greater command of the communication and social-psychological skills needed for building social contacts and constructing stable social relationships (McPherson et al. 2006) and lifestyle practices (Pampel et al. 2010). Finally, although education precedes and influences people's employment, earnings and income, its beneficial effects on people's health and wellbeing are mediated in part by the lower financial distress and the better and more secure employment conditions (Ross and Wu 1995) that having higher education tends to provide. Indeed, most studies have reported that there is a positive association between education and happiness even when income is controlled for (Blanchflower and Oswald 2004), and that highly educated individuals tend to choose types of activities - physical, social, cultural that positively affect life satisfaction (Fernández-Ballesteros et al. 2001).

The evidence on the question of how wellbeing inequalities unfold across age groups has been more mixed (Yang 2008). Theoretically, the development of wellbeing over the life course across groups is related to the following: first, structural differences in the starting points of groups; second, the existence of processes of accumulation of advantages/disadvantages; and, third, group differentials in exposure to life events that are also strongly correlated with age, such as marriage and childbearing, or the evolution of an individual's health status, labour market attachment and income. There is evidence that the most critical life events tend to affect women more negatively than men. For example, compared to men, women tend to face more challenges in reconciling work and family, and they are more likely to be widowed. In addition, critical events known to affect wellbeing (such as unemployment or divorce) tend to produce more negative outcomes for women than for men (Keizer et al. 2010; Madero-Cabib and Fasang 2016; Melchior et al. 2007; Troxel et al. 2010). If gender roles and behaviour shift during the life course, the wellbeing gap between men and women linked to those events also varies. Indeed, longitudinal studies have suggested that gender differences in happiness vary across age groups. It has, for example, been shown that prior to reaching middle age, women are happier than men; but that this pattern reverses as people grow older and experience particular events or transitions (Yang 2008). Thus, it may be the case that, on average, men and women start with an even distribution of wellbeing, but then experience gender-specific transitions differently and with different consequences, which causes their trajectories of wellbeing to diverge at older ages.

More comprehensive social stratification theories, such as the cumulative (dis)advantage (CAD) theory (Dannefer 2003; DiPrete and Eirich 2006), predict that disparities in wellbeing increase over the life course because early disadvantages

\footnotetext{
Higher educational attainment might also enhance a person's expectations for achievement, and increase her standards when evaluating her life satisfaction.
} 
accumulate with age. The CAD theory argues that the benefits associated with a person's structural position early in the life course tend to gradually accumulate over time, through a path-dependent process that links trajectories earlier in life to outcomes later in life. This implies that the social differences between groups tend to widen as they age (DiPrete and Eirich 2006; McDonough et al. 2015). Initial individual differences in race, gender or socioeconomic origin generate structures of opportunity and pathways that further differentiate individuals over time. Early life course heterogeneities can therefore become greater over the life course. By contrast, the "age-as-leveller" theory (Lynch 2003) posits that with age, the resources that generated and reinforced the disparities earlier in life matter less and less for life satisfaction, as people's attachment to the labour market and their social relationships weaken.

In their meta-analysis, Pinquart and Sörensen (2001) showed that the gender gap in subjective wellbeing and self-concept, although smaller than expected, increases with age. This gap has been attributed to the disadvantages women suffer in terms of their everyday competences, their health and socioeconomic conditions, and their greater likelihood of being widowed in old age. It has generally been shown that the self-rated and physical health trajectories of men and women differ substantially over the life course (McDonough et al. 2015; Oncini and Guetto 2018). There is also evidence suggesting that education-related health disparities grow across the life span, or at least until people reach their mid-sixties, when the divergence attenuates (Mirowsky and Ross 2007; Ross and Wu 1995; Prus 2004; Lee et al. 2016). Mirowsky and Ross (2005) argued that education put people onto a track that permeates all aspects of life. The cumulative beneficial effects of higher education on health over time are evident when we look at a range of factors: socioeconomic status, behaviours, psychological health, anatomical health and "perhaps intracellular" characteristics (2005: pp. 27). Moreover, these factors interact over the life course to amplify the beneficial effects of education (Mirowsky and Ross 2007). In contradiction to the body of literature that has supported the notion that disadvantages accumulate over the life course (Mayer 2009), and in line with the age-as-leveller theory, Yang (2008) showed that in the US, gender and educational (but not racial) inequalities in happiness decline with age. Yang (2008) argued that these social differences are attenuated by the differential exposures of these groups to correlates of happiness, such as retirement, widowhood and eligibility for social benefits. The loss of social support and integration tends to reduce these differences at older ages because it erodes the advantages of some groups relative to others (Yang 2008: pp. 221). Thus, it appears that the gender and educational gaps in subjective wellbeing decrease with rising age.

\subsection{The French and Swiss contexts}

Existing studies have documented that gender and educational health and wellbeing inequalities vary between countries (Huisman et al. 2003, Von dem Knesebeck etal. 
Table 1:

Main demographic and labour market indicators. France and Switzerland (2018)

\begin{tabular}{lcc}
\hline & France & Switzerland \\
\hline Crude marriage rate (per 1000) & 3.5 & 4.8 \\
Total fertility rate & 1.88 & 1.52 \\
Out-of-wedlock births & $60.4 \%$ & $25.7 \%$ \\
Male unemployment & $8.7 \%$ & $4.3 \%$ \\
Female unemployment & $8.8 \%$ & $5.1 \%$ \\
Female labour force participation rate & $74.4 \%$ & $82.4 \%$ \\
Female part-time employment share & $28.7 \%$ & $63 \%$ \\
Government health expenditure (\% GDP) & $8.1 \%$ & $2.2 \%$ \\
\hline
\end{tabular}

Source: Elaboration of the authors based on Eurostat 2020.

2006; Bambra et al. 2009). While inequalities in conservative welfare states - such as Switzerland and France - tend to be smaller than they are in other regimes, they are still present (Eikemo et al. 2008). Moreover, despite belonging to the same welfare regime classification, the two countries differ with respect to fundamental aspects related to inequality.

First, Switzerland and France differ in terms of their gendered family and labour market institutions. Table 1 displays the main demographic and labour market indicators for the two countries (Eurostat). ${ }^{2}$ Marriage rates are higher in Switzerland (4.8 per 1000) than in France (3.5 per 1000), but while France's fertility rates are among the highest in Europe (1.88 children per woman in 2018), Switzerland's fertility rates are much lower, close to those of Eastern and Southern European countries (1.52 children per woman in 2018). However, in relation to family norms, the most striking difference between the two countries lies in the share of births that take place outside of wedlock (mostly in cohabitation): 60.4\% in France versus $25.7 \%$ in Switzerland. When we look at the countries' labour markets, we see that overall unemployment rates are much lower in Switzerland than in France. However, whereas in France the male and female unemployment rates are equal $(8.7 \%$ and $8.8 \%$, respectively), in Switzerland, the female unemployment rate is $25 \%$ higher than the male unemployment rate $(4.3 \%$ and $5.1 \%)$. Moreover, even though female labour force participation is quite high in both countries $(82.4 \%$ in Switzerland and $74.4 \%$ in France), the share of women in part-time work in the two countries differs tremendously, at $63 \%$ in Switzerland and $28.7 \%$ in France.

2 We report data for the most recent available year at the time of writing, 2018; but the differences between France and Switzerland were similar in 2006. For instance, the marriage rates were 4.3 (FR) and $5.3(\mathrm{CH})$; the TFRs were $1.98(\mathrm{FR})$ and $1.46(\mathrm{CH})$; the male and the female unemployment rates were $8.2 \%(\mathrm{FR})$ and $4.5 \%(\mathrm{CH})$ and $9.5 \%(\mathrm{FR})$ and $5.2 \%(\mathrm{CH})$, respectively; and the government health expenditures were $7.6 \%(\mathrm{FR})$ and $1.7 \%(\mathrm{CH})$. 
In Switzerland, a traditional gender model tends to be much more dominant, which implies that family responsibilities are borne almost entirely by women. Thus, compared to men, women in Switzerland end up having a weaker and irregular labour market attachment over their life course, which exposes them to greater financial insecurity (Widmer et al. 2003). In France, by contrast, the dual earner model is widespread, including among parents (Fagnani 2010). In Switzerland, the incentives for following a traditional male breadwinner-female caretaker model include gender-segregated labour markets, large gender wage gaps and high marginal tax rates that penalise second earners (Cooke and Baxter 2010; Peters 2014). Moreover, in Switzerland, public child care is limited and expensive, which creates significant trade-offs between employment and care time for mothers (Wall and Escobedo 2013). By contrast, the French welfare state has long been oriented towards the promotion of women's full employment through a number of family policies that allow families to pursue diverse employment-family reconciliation strategies, such as the provision of broad access to child care facilities (Fagnani 2010), as well as family benefits that encourage couples to have a large number of children (Pailhé et al. 2008).

Second, Switzerland has the most privatised health system in Europe. Based on universal private insurance, the Swiss system has one of the highest shares of outof-pocket health expenditures in the OECD. France, by contrast, has a compulsory public insurance programme that covers the cost of medical treatment by private doctors, while limiting doctors' fees. Indeed, as Table 1 shows, government spending on the health care system is relatively high in France $(8.1 \%$ of gross domestic product, GDP in 2018), and is relatively low in Switzerland (2.2\% of GDP in 2018).

\section{Data and method}

In our analysis, we use data from the Santé et Itinéraire Professionnel (SIP) and the Swiss Household Panel (SHP). The SIP survey was conducted among individuals aged 20 to 74 in 2006 living in ordinary households in mainland France. Two waves (2006 and 2010) are available. The Swiss Household Panel is a random sample of private households in Switzerland in which all members of the family aged $14+$ are interviewed annually. The SHP has 20 waves (1999-2018), but to ensure comparability, we used the 2006 wave for both surveys. We decided to use the 2006 wave instead of the 2010 wave for two main reasons. First, compared to the data from the 2010 wave, the French and Swiss panel data from the 2006 wave either are not or are less affected by attrition, and the samples are larger. ${ }^{3}$ Second, while there

\footnotetext{
3 After the initial sample of 1999 respondents, a refreshment sample was added to the SHP in 2004 to partially compensate for attrition, which was just two years before our wave of 2006. The SIP is also a panel, but given that we use its first wave, we do not have problems of attrition for the French data.
} 
is no reason to expect to observe significant differences between the two waves since they are only few years apart, cross-sectional findings based on the 2010 wave could be affected by the financial crisis of 2008-2009. The recession had heterogenous effects on health and wellbeing across contexts and social groups that are not the focus of this study (Burgard and Kalousova 2015). We considered individuals of working ages (aged 25-69) in order to further limit the impact of attrition in the Swiss data, and because one of the dimensions of wellbeing we are interested in is professional satisfaction $(N=2136$ for men and $N=2753$ for women for Switzerland and $N=4367$ for men and $N=5300$ for women for France).

We focused on four outcomes of physical and mental health: self-reported health; daily activity limitations; depressive symptoms and sleep disorders; and two relational wellbeing indicators: satisfaction with social relationships (reliability of the social network in the SIP) and satisfaction with professional life. These measures were chosen because they provide information about similar health and wellbeing domains across the two surveys. However, as we mentioned, some important differences in terms of how the specific questions were phrased and the responses were coded persist, which limit their direct cross-country comparability. The first difference between the two surveys concerns the time frame the questions refer to. Table 2 reports the specific questionnaire formulations in the two surveys. In the French SIP, most of the health questions refer to a specific time frame, albeit one that varies across items: six weeks for depressive symptoms, six months for daily activity limitations and 12 months for sleeping problems. The Swiss SHP, by contrast, only uses a specific time frame (of four weeks) for sleeping disorders, while all of the other questions are posed in more general terms.

The second difference between the two surveys relates to the operationalisation of the responses. Table 3 reports the summary statistics of the main variables in the two surveys. For health status, the responses vary in the two surveys on a scale from one (very well) to five (not well at all), and are recoded in the opposite direction for both countries so that higher values mean better health. For work satisfaction, the responses vary on a scale of $0-10$. All of the other indicators in the SIP data are binary $(0 / 1)$. However, while sleep disorders were originally measured on a scale of $1-4$, they are also used as a binary variable indicating whether the individual has had sleeping problems for at least several days a week. By contrast, in the SHP, the variables for satisfaction with social relationships, feelings of depression, and daily activity limitations are measured on a scale of $0-10$, while sleep disorders are measured on a scale of one (not at all) to three (very much).

These phrasing and measurement differences limit the comparability of the levels of the indicators both between the two countries (e.g.: asking whether French women of different ages suffer from more or fewer sleeping problems than their Swiss counterparts) and within the countries. However, our primary research interest lies not in performing cross-country comparisons, but rather in illustrating the age trends and providing within-country comparisons across gender and educational groups. Therefore, we do not expect the different formulations of the questions to invalidate our analyses. 
Table 2:

Questionnaire formulation in SIP (France) and SHP (Switzerland)

\begin{tabular}{|c|c|c|}
\hline & SIP & SHP \\
\hline Self-reported health & $\begin{array}{l}\text { How is your health status } \\
\text { overall? } 1 \text { means "very } \\
\text { well" and } 5 \text { "very bad" }\end{array}$ & $\begin{array}{l}\text { How do you feel right now? } 1 \\
\text { means "very well" and } 5 \text { means } \\
\text { "not well at all" }\end{array}$ \\
\hline $\begin{array}{l}\text { Daily activity } \\
\text { limitations }\end{array}$ & $\begin{array}{l}\text { Have you been limited for } \\
\text { at least } 6 \text { months because } \\
\text { of health problems in your } \\
\text { daily activities? } \\
1 \text { means "yes" and } 2 \\
\text { means "no" }\end{array}$ & $\begin{array}{l}\text { Please tell me to what extent, } \\
\text { generally, your health is an } \\
\text { impediment in your everyday } \\
\text { activities (in your housework, } \\
\text { your work or leisure activities); } \\
0 \text { means "not at all" and } 10 \\
\text { means "a great deal". }\end{array}$ \\
\hline Sleep disorders & $\begin{array}{l}\text { Have you had sleeping } \\
\text { problems (difficulties in } \\
\text { falling asleep, waking up } \\
\text { during the night. ..) in the } \\
\text { past } 12 \text { months? From } 1 \\
\text { "never or rarely" to } 4 \\
\text { "almost every day" }\end{array}$ & $\begin{array}{l}\text { During the last } 4 \text { weeks, have } \\
\text { you suffered } \\
\text { from any of the following } \\
\text { disorders or health problems? } \\
\text { "not at all", "somewhat", "very } \\
\text { much"? } \\
\text { Difficulty in sleeping, or } \\
\text { insomnia }\end{array}$ \\
\hline $\begin{array}{l}\text { Depressive } \\
\text { symptoms }\end{array}$ & $\begin{array}{l}\text { During the last } 6 \text { weeks, } \\
\text { have you felt particularly } \\
\text { sad, depressed, most of the } \\
\text { time of the day, most days? } \\
1 \text { means "yes" and } 2 \\
\text { means "no" }\end{array}$ & $\begin{array}{l}\text { Do you often have negative } \\
\text { feelings such as having the } \\
\text { blues, being desperate, suffering } \\
\text { from anxiety or depression, if } 0 \\
\text { means "never" and } 10 \text { means } \\
\text { "always"? }\end{array}$ \\
\hline $\begin{array}{l}\text { Satisfaction with } \\
\text { social network/ } \\
\text { relationship }\end{array}$ & $\begin{array}{l}\text { Do you have someone you } \\
\text { can rely on to discuss } \\
\text { personal matters or make a } \\
\text { difficult decision? } 1 \text { means } \\
\text { "yes" and } 2 \text { means "no" }\end{array}$ & $\begin{array}{l}\text { How satisfied are you with your } \\
\text { personal relationships, if } 0 \\
\text { means "not at all satisfied" and } \\
10 \text { means "completely } \\
\text { satisfied"? }\end{array}$ \\
\hline $\begin{array}{l}\text { Satisfaction with } \\
\text { work }\end{array}$ & $\begin{array}{l}\text { Overall, are you satisfied } \\
\text { with your professional } \\
\text { career? } 0 \text { means "I don't } \\
\text { agree at all" and } 10 \text { means } \\
\text { "I totally agree" }\end{array}$ & $\begin{array}{l}\text { On a scale from } 0 \text { "not at all } \\
\text { satisfied" to } 10 \text { "completely } \\
\text { satisfied", can you indicate your } \\
\text { degree of satisfaction for each } \\
\text { of the following points? } \\
\text { Your job in general }\end{array}$ \\
\hline
\end{tabular}

Source: Elaboration of the authors based on SIP and SHP 2006 questionnaires.

We studied separately for the two countries the association between age and the multiple measures of health and wellbeing by gender and socioeconomic status. Ages from 25 to 69 were grouped into five-year categories to allow some degree of flexibility in the association between age and health and wellbeing, but without 
Table 3:

Summary statistics SIP (France) and SHP (Switzerland)

\begin{tabular}{|c|c|c|c|c|c|c|}
\hline Variables & Units & Obs & $\begin{array}{c}\text { Mean/ } \\
\text { Proportion }\end{array}$ & Std.Dev. & Min & Max \\
\hline \multicolumn{7}{|l|}{ SIP, France } \\
\hline Satisfaction with career & Mean & 9369 & 7.394 & 2.227 & 0 & 10 \\
\hline Health status & Mean & 9480 & 3.919 & 0.838 & 1 & 5 \\
\hline Someone to rely on & Proportion of yes & 9480 & 0.907 & 0.290 & 0 & 1 \\
\hline Sleep disorders & Proportion of yes & 9480 & 0.262 & 0.440 & 0 & 1 \\
\hline Activity limitations & Proportion of yes & 9480 & 0.162 & 0.368 & 0 & 1 \\
\hline Depressive symptoms & Proportion of yes & 9480 & 0.262 & 0.439 & 0 & 1 \\
\hline \multicolumn{7}{|l|}{ Gender } \\
\hline Men & & 4291 & 45.26 & & & \\
\hline Women & & 5189 & 54.74 & & & \\
\hline \multicolumn{7}{|l|}{ Education } \\
\hline $\begin{array}{l}\text { Primary or lower } \\
\text { secondary }\end{array}$ & & 5499 & 58.01 & & & \\
\hline Upper secondary & & 1488 & 15.70 & & & \\
\hline Tertiary & & 2493 & 26.30 & & & \\
\hline \multicolumn{7}{|l|}{ Age } \\
\hline 25-29 & & 634 & 6.56 & & & \\
\hline $30-34$ & & 869 & 8.99 & & & \\
\hline $35-39$ & & 1141 & 11.80 & & & \\
\hline $40-44$ & & 1212 & 12.54 & & & \\
\hline $45-49$ & & 1255 & 12.98 & & & \\
\hline $50-54$ & & 1397 & 14.45 & & & \\
\hline $55-59$ & & 1395 & 14.43 & & & \\
\hline $60-64$ & & 985 & 10.19 & & & \\
\hline $65-69$ & & 779 & 8.06 & & & \\
\hline \multicolumn{7}{|l|}{ SHP, Switzerland } \\
\hline Satisfaction with the job & Mean & 3863 & 8.077 & 1.463 & 0 & 10 \\
\hline Health status & Mean & 4889 & 4.028 & .639 & 1 & 5 \\
\hline $\begin{array}{l}\text { Satisfaction with } \\
\text { social relationship }\end{array}$ & Mean & 4889 & 8.141 & 1.515 & 0 & 10 \\
\hline Sleep disorders & Mean & 4889 & 1.429 & .652 & 1 & 3 \\
\hline Activity limitations & Mean & 4889 & 1.75 & 2.481 & 0 & 10 \\
\hline Depressive symptoms & Mean & 4889 & 2.124 & 2.083 & 0 & 10 \\
\hline \multicolumn{7}{|l|}{ Gender } \\
\hline Men & & 2136 & 43.69 & & & \\
\hline Women & & 2753 & 56.31 & & & \\
\hline
\end{tabular}

Continued 
Table 3:

Continued

\begin{tabular}{|c|c|c|c|c|c|c|}
\hline Variables & Units & Obs & $\begin{array}{c}\text { Mean/ } \\
\text { Proportion }\end{array}$ & Std.Dev. & Min & Max \\
\hline \multicolumn{7}{|l|}{ Education } \\
\hline $\begin{array}{l}\text { Primary or lower } \\
\text { secondary }\end{array}$ & & 292 & 5.97 & & & \\
\hline Upper secondary & & 2814 & 57.56 & & & \\
\hline Tertiary & & 1783 & 36.47 & & & \\
\hline \multicolumn{7}{|l|}{ Age } \\
\hline $25-29$ & & 340 & 6.95 & & & \\
\hline $30-34$ & & 426 & 8.71 & & & \\
\hline $35-39$ & & 617 & 12.62 & & & \\
\hline $40-44$ & & 791 & 16.18 & & & \\
\hline $45-49$ & & 708 & 14.48 & & & \\
\hline $50-54$ & & 599 & 12.25 & & & \\
\hline $55-59$ & & 529 & 10.82 & & & \\
\hline $60-64$ & & 472 & 9.65 & & & \\
\hline $65-69$ & & 407 & 8.32 & & & \\
\hline
\end{tabular}

Source: Elaboration of the authors based on SIP and SHP 2006 questionnaires.

over-specifying the model with year-dummies. We focused on respondents aged 25 69 to ensure that the respondents' education had been completed, and to exclude the oldest old, whose participation in the survey would have been even more selected based on health reasons than was the case for the other age groups. Education is a widely applied measure of socioeconomic position that reflects people's material and non-material resources, and that precedes their labour market and income prospects. We recoded education into three categories: primary or lower secondary, upper secondary and tertiary education. However, for the sake of clarity, we present in the figures only the findings for the low and the high educated.

The statistical analyses conducted in this study are based on the Ordinary Least Squares (OLS) method. We use linear regression models for continuous dependent variables and linear probability models for the binary health indicators in the SIP. Logistic regressions were also performed and provided similar results. However, we decided to show the results of the linear probability models because they are easier to interpret. We use cross-sectional weights corresponding to the countries' populations. We do not control for socioeconomic variables, such as marital or employment status, because we are interested in the total association between age and health and wellbeing, and part of this association is indirectly convened by the expedience of such life course events at given ages (Easterlin 2006). We report our findings here by graphically showing predicted health and wellbeing by age 
groups in the two countries, while the complete tables are included the appendix (Tables A.2-A.5).

\section{Results}

Results from models with age-gender (Figures 1-2) and age-education (Figures 3-4) interactions (although many interaction terms do not reach statistical significance) show that in both France and in Switzerland and in all groups, people's overall health status and physical health clearly deteriorate at older ages, while the trends in mental health vary more depending on gender and education. In France, the two measures of relational wellbeing display opposite age trends: i.e., the reliability of people's social networks steadily drop with age, while people's satisfaction with their career increases with tenure. In Switzerland, levels of relationship satisfaction are quite constant across age groups, while job satisfaction increases significantly at very old ages only.

\subsection{Gender inequalities in general health}

All in all, the gender differences seem small. For example, in Switzerland, women have a significantly worse perceived health status than men early in their life course (age 25-29), as well as in their fifties. In France, levels of self-rated health are rather similar among men and women, with the latter reporting significantly lower levels of health only at ages 35-39. The overall decline with age is quite pronounced for both French men and women. Our estimates indicate that from early adulthood to retirement age, self-perceived health in France declines from around 4.3 (between well and very well) to around 3.6 (between well and average). In contrast, while Swiss men's self-rated health status does not change significantly after age 30, remaining above four (between well and very well), Swiss women's self-rated health status is lower in the age groups after age 50 (around 3.8, between well and average) than it is in their thirties (above four, in line with men's status). An increase in physical limitations with age can be observed among both men and women in France: by age 60, both have a probability of reporting limitations of between $20 \%$ and $30 \%$, compared with a probability below $10 \%$ as young adults. Only Swiss women report a significant increase in limitations, such that by age 65, their impediment levels are almost twice as high (around three on a 0-10 scale) as those of younger women (1.5).

\subsection{Gender inequalities in mental health}

Greater gender inequalities emerge when we look at indicators of mental health. Women report a higher frequency of both sleeping disorders and depressive 


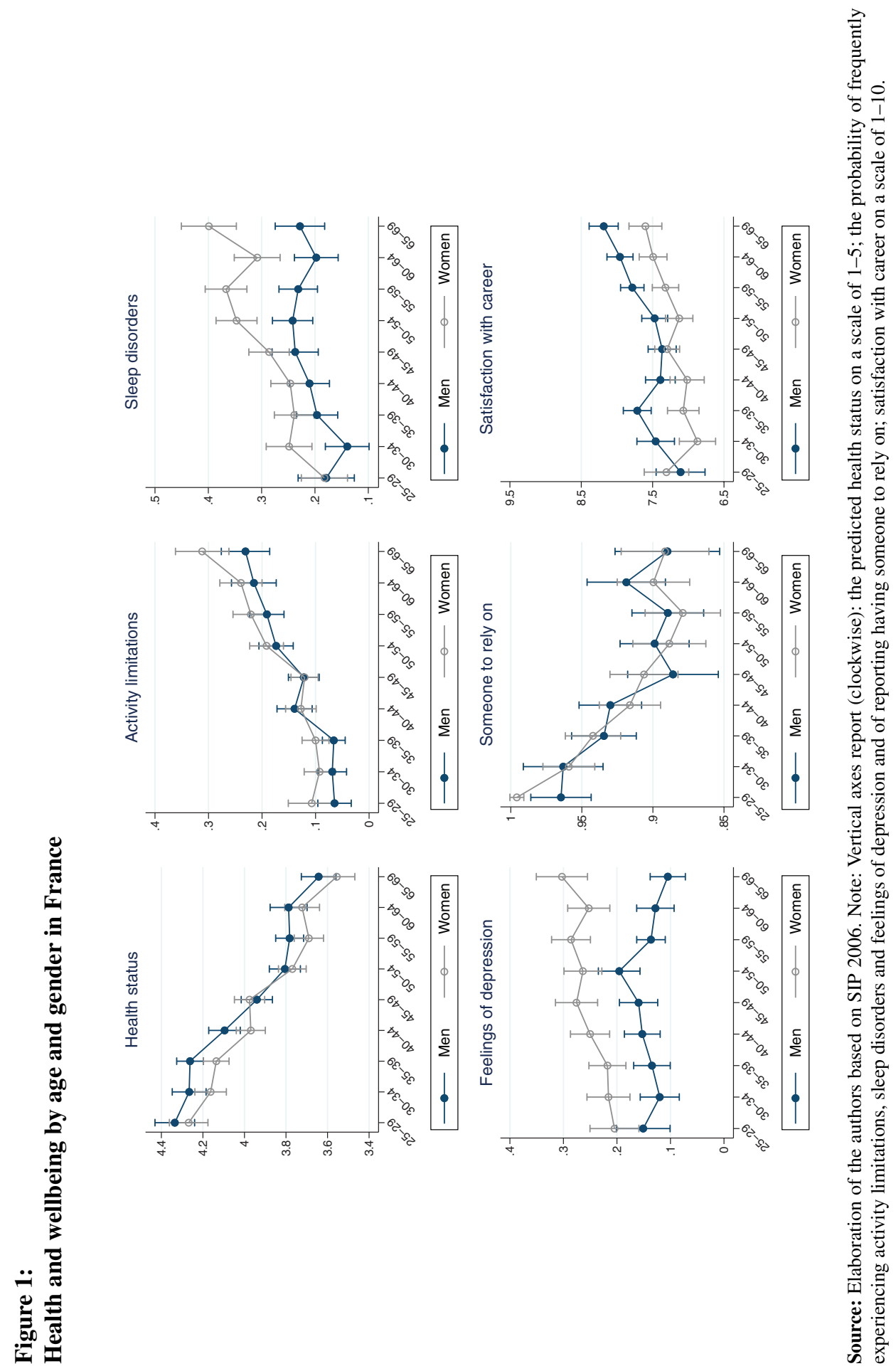




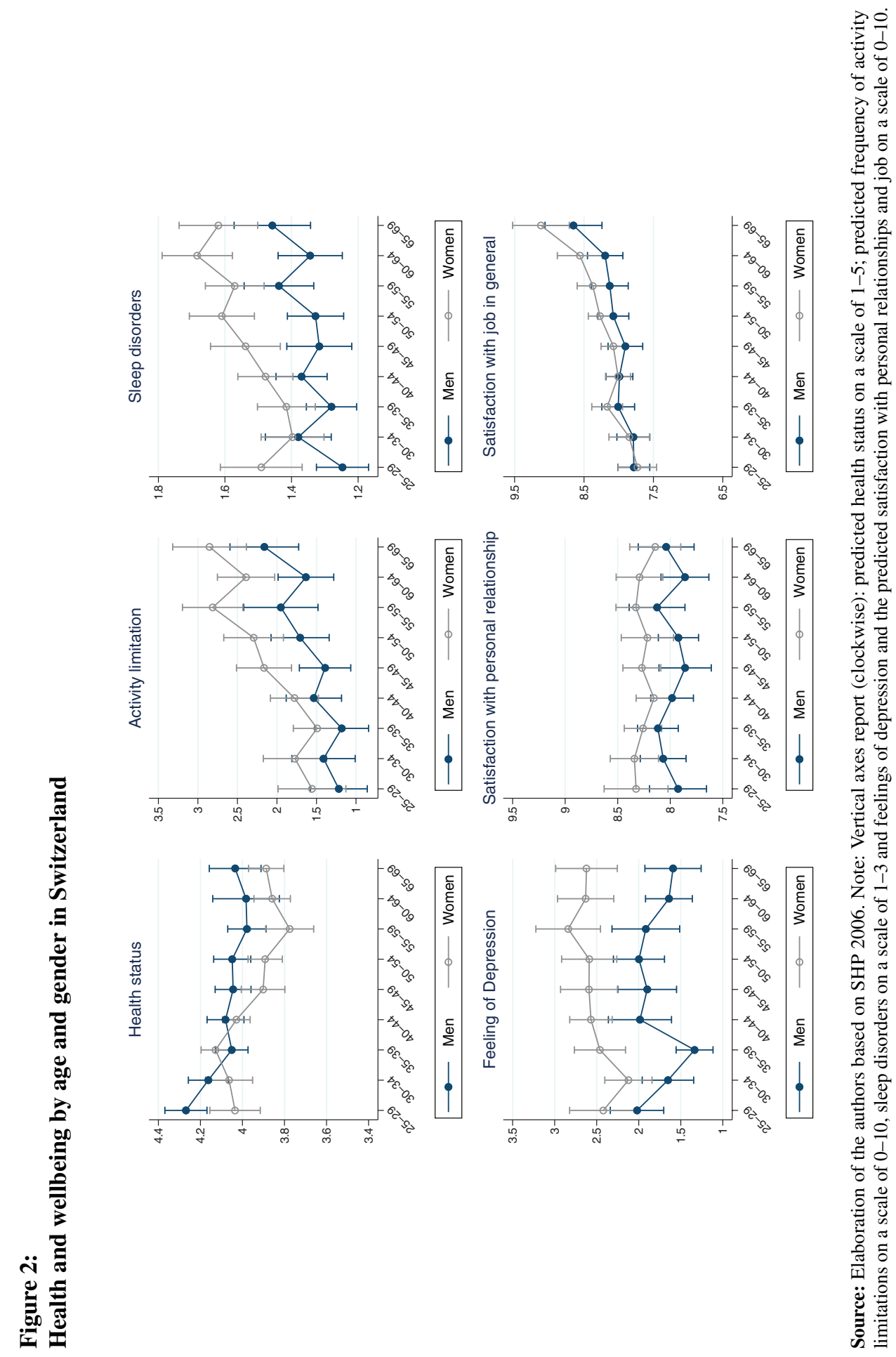




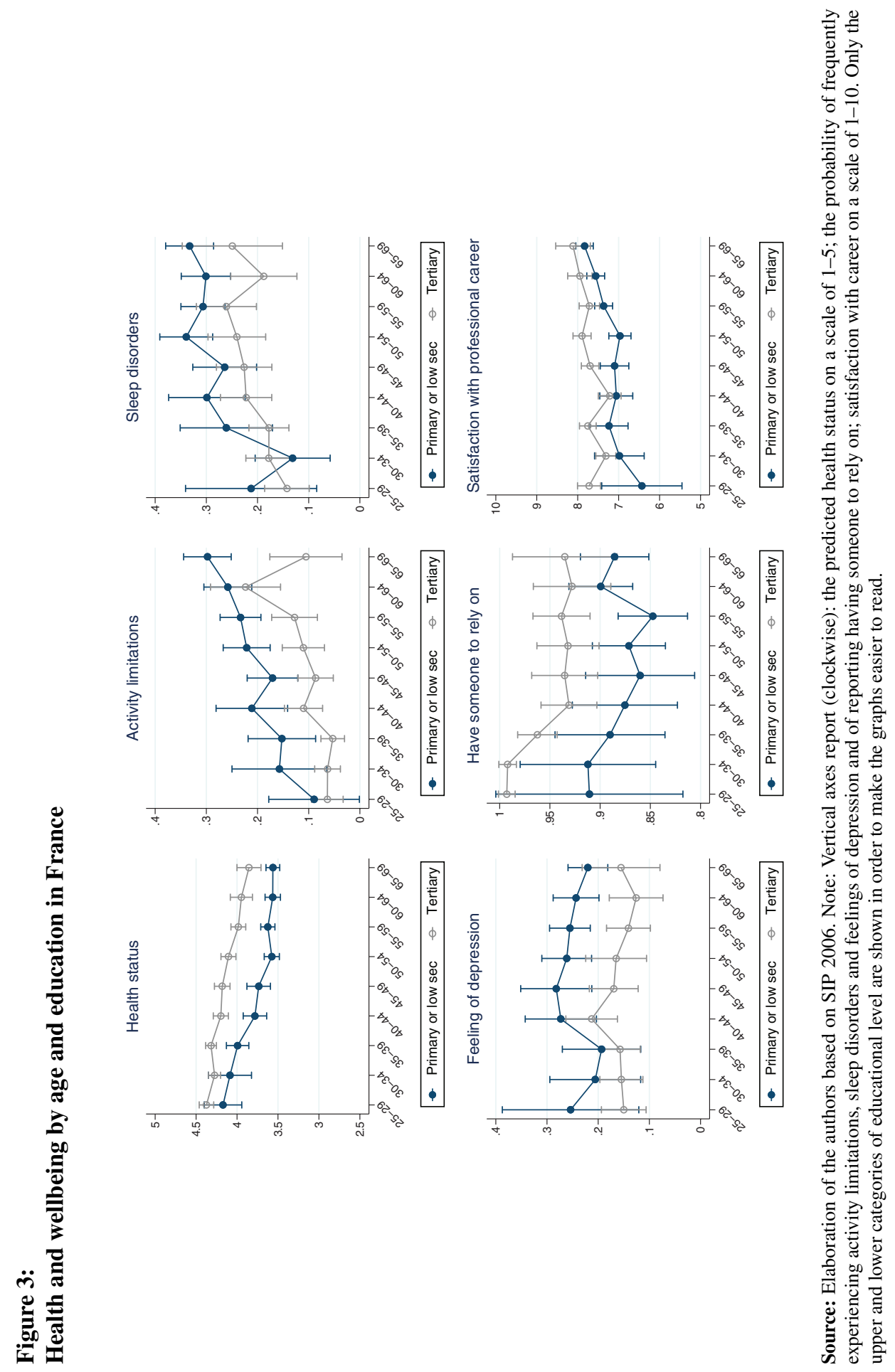



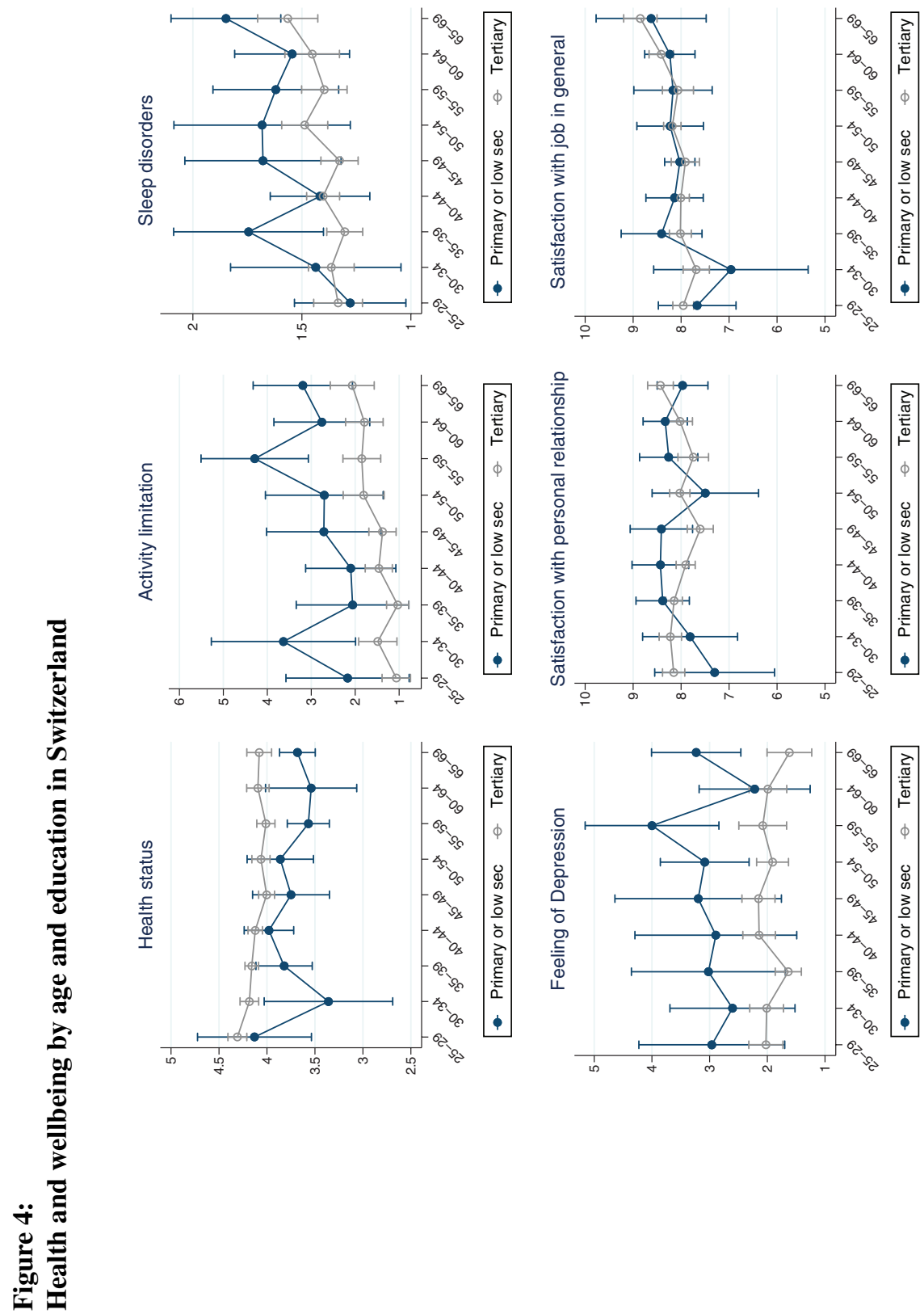

:

实

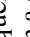

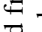

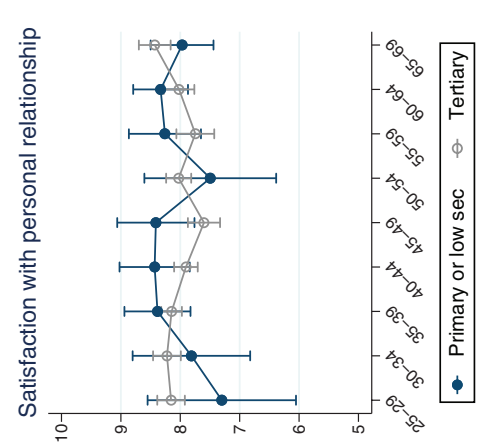

马्य

월

范

苛

흥

응

형

4

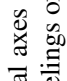

总造

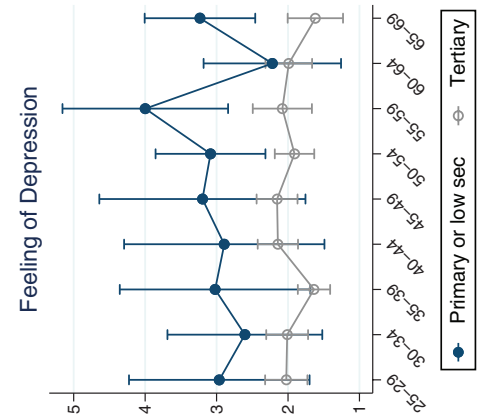

ํำ

Z

ठํํㅇ

完

空

ธี

D

के

吾

¿ !

पै

.ี ํㅗㄹ

ปี

피 告

㖕高 
symptoms, and the gap seems to widen among older age groups in both countries. In particular, women report greater sleeping problems than men at younger ages (at ages 25-29 in Switzerland and at ages 30-34 in France), and quite consistently after age 45 in Switzerland and age 50 in France. The trends are clearly diverging in France, where the probability of suffering from frequent sleep disorders (dichotomous scale) reaches $40 \%$ among women and only slightly more than $20 \%$ among men. Despite the large confidence intervals and the rather low overall incidence (always below two, somewhat), in Switzerland, the frequency of sleep disorders (13 scale) increases more with age for women than for men. In France, feelings of depression increase similarly for men and women up to their early fifties, but start diverging at older ages. Compared to their male counterparts, French women in the 65-69 age group have three times the probability of reporting feelings of depression (dichotomous scale). In Switzerland, the gender gap in depressive symptoms (010 scale) increases first among the 25-35 age groups, mostly due to declining symptoms among men. Thereafter, the gender gap again becomes pronounced after the age of 55 .

\subsection{Gender inequalities in relational wellbeing}

In France, the probability of having someone to rely on (dichotomous scale) is significantly lower in the age groups over age 45 than it is for young adults, but the magnitude of the decline is quite small, and the trends do not differ significantly among men and women. In Switzerland, relational wellbeing does not seem to change much across age groups, remaining in the range of 8-8.5 (out of 10). Swiss women tend to report higher levels of satisfaction with social relationships than Swiss men, but the difference is statistically significant only in two age groups (5054 and 60-64), and it is very small in magnitude (Table A.3). The differences in the age trends in relational wellbeing between the two countries might be related to the wording of the question in the two surveys: i.e., as having someone to rely on is more strongly linked to isolation and lack of independence among the elderly, we can expect this item to be more negatively associated with age than the overall satisfaction with social relationships.

Job satisfaction tends to rise with age in both countries (by around one point on a $0-10$ scale), although the age differences are statistically significant only in the older age groups who are close to or older than the retirement age (Tables A.2 and A.3). An interpretation of this finding might be that the men and women who keep working after retirement age are those who enjoy it the most. More surprisingly, we observe no substantial gender differences in job satisfaction in Switzerland. Meanwhile, in France, women consistently report having lower levels of career satisfaction than men in most age groups, except in their forties and early fifties, due to a significant decline in men's levels of career satisfaction in those age groups. The differences found between countries might again be due to the different wording of the questions. Feelings of satisfaction with one's professional career more clearly 
reflect an evaluation of the professional opportunities of the individual, which might explain the pronounced gender differences found in France. Satisfaction with one's job in general might additionally reflect the type and the quality of the job, as well as working conditions, flexibility and economic conditions, which might have diluted the gender heterogeneities found in Switzerland.

\subsection{Educational inequalities in general health}

In both countries, important socioeconomic inequalities emerge when we consider measures of general and physical health, with lower educated individuals displaying worse health than higher educated individuals across most age groups. ${ }^{4}$ Primary educated individuals have a significantly lower self-reported health status than tertiary educated individuals in all age groups except for the youngest one in France, and the difference is especially pronounced in mid-life, at ages $40-54$, where the difference is around one point on a 1-5 scale. In Switzerland, the overall health of the tertiary educated individuals remains stable across age groups, and is constantly above that of the primary educated individuals. The confidence intervals are large ${ }^{5}$ and the differences are small in magnitude, but a significant educational gap can nonetheless be observed for the 30-39 and 55+ age groups. In both countries, individuals with primary education also report greater activity limitations at ages 30-39, and especially after ages 50-54. With the exception of the 60-64 age group, a divergent trend is observed in France, whereas the confidence intervals for the primary educated in Switzerland are too large to allow us to draw conclusions.

\subsection{Educational inequalities in mental health}

Socioeconomic inequalities also emerge when we look at measures of mental health. Lower educated individuals display significantly higher levels of sleep disorders only at ages 35-39 in Switzerland and at ages 60-64 in France, and we see a slight trend towards increasing sleep problems for both socioeconomic groups and in both countries. The estimates show that depressive symptoms tend to be higher among the primary educated, especially after age 50 . Due to the large confidence intervals, we cannot conclude that the gap in mental health across socioeconomic groups is widening at older ages, but we can definitely confirm that it does not shrink.

\footnotetext{
4 To make the graphs more easily readable, Figures 3-4 omit the (intermediate) trends for the upper secondary educated respondents.

5 Table A.1 in the appendix shows that there are few respondents with primary education in Switzerland, and the cell size gets very small once they are divided by age groups.
} 


\subsection{Educational inequalities in relational wellbeing}

Individuals' levels satisfaction with their social relationships and with their jobs do not change between age groups in Switzerland, and the trends are basically identical across educational levels. For France, the confidence intervals are quite large for the primary educated, so definite conclusions are difficult to draw. However, the tertiary educated in France seem to report higher relational reliability, with statistically significant differences only at ages 30-39 and 55-59; and higher levels of career satisfaction, albeit only in the 50-54 age group (Tables A.4 and A.5).

Only the upper and lower categories of educational level are shown in order to make the graphs easier to read.

\section{Discussion}

Ensuring a satisfying quality of life throughout the life course means not only remaining in good physical and mental health and having sufficient financial means, but also maintaining high levels of overall and relational satisfaction. All of these dimensions contribute to the overall construct of wellbeing. There is increasing evidence that there are growing inequalities in wellbeing in contemporary societies albeit with large contextual differences - which strongly suggests that researchers and policy-makers should focus on reducing demographic and socioeconomic gaps in quality of life.

The main contribution of our study was to show how unequally wellbeing is distributed across social groups, and how such inequalities develop over age in two different contexts. We were particularly interested in examining how different dimensions of physical and mental health and relational wellbeing heterogeneously develop with age. We exploited two rich household surveys, SIP and SHP, to examine the development of health and wellbeing across age by gender and education in France and Switzerland. Our assumption was that analysing these trends in different contexts could provide insights into the social and institutional differences in the determinants of health and wellbeing trajectories. Despite both being rich European societies with conservative welfare regimes, France and Switzerland differ in two crucial domains: namely, in their prevailing gendered family and labour market institutions and in the nature and accessibility of their health care systems (Cullati 2015).

Before examining our findings, it is important to consider that our study had a few limitations. First, the questions on health and wellbeing were phrased differently in the questionnaires of the two surveys. Nevertheless, we believe that these measures provided reliable information for examining age trends in health and wellbeing across gender and education within countries. Interestingly, some wording differences between the two surveys even allowed us to explore various aspects of the same indicator. For instance, questions about work satisfaction in the SIP asked specifically about career, while the SHP asked about overall 
job satisfaction. Our finding of a large gender gap in France suggests (among other plausible explanations outlined below) that it is the specific aspect of career progression that causes women to feel much less satisfied than men, even in a context like France, which ranks relatively high in terms of gender equality.

Another important difference in how the questions on health and wellbeing were phrased in the two surveys was in the time frames they referred to. While most of the questions in the French survey referred to a specific time frame, most of the questions in the Swiss survey were phrased in general terms. This difference might have had some implications for the observed inequalities. Overall, the differences across age groups might have been smaller and the estimates might have been more prone to measurement error in Switzerland, where the questions were more general. It is also important to keep in mind that all of our measures of health and wellbeing were self-reported. This means that differences in reporting behaviour by age, gender or education might have played a role in the observed differences. While recent studies found no systematic gender or educational differences in reporting either good or bad health, they found a declining concordance between self-reported and actual health with age among older respondents (Spitzer and Weber 2019; Oksuzyan et al. 2019), although much less so among younger adults (Miilunpalo et al. 1997; Pursey et al. 2014).

The second limitation of our study was its cross-sectional nature. This means that our findings reflect differences between individuals of different ages in 2006, and not the effect of the ageing process within the individual. Healthier and happier individuals tend to live longer and participate longer in surveys; therefore, our older respondents were selected in terms of higher wellbeing. This might have led us to underestimate the age differences, especially in the Swiss data (2006 is the first wave of the SIP), as well as the education gap, given that the health selection mechanism tended to be stronger among the lowest socioeconomic strata of the population. Relatedly, because of the cross-sectional character of our analysis and the wellknown age-period-cohort problem, we could not distinguish between the age and the cohort effects on health and wellbeing (Bell and Jones 2014).

The final limitation of our analyses was the low number of observations - again, especially in the SHP, and especially in the group of primary educated respondents which prevented us from providing statistically sound estimates for these groups, and from further exploring the gender and educational inequalities.

Despite these limitations, we can draw important conclusions from our analysis. We found crucial heterogeneities across indicators, and depending on the types of inequalities we looked at. Our results indicated that in both countries, overall and physical health deteriorated across age groups. We found gender inequalities in physical health only in Switzerland, but a rather large socioeconomic divide in both countries. The educational gap was shown to be largest in mid-life, which might be explained by the different degrees of physical effort required in the types of work the lower and the highly educated individuals did. The low skilled workers tended to have more physically demanding jobs, and this might have affected their health, even though no cumulative effects were observed (although, as we noted above, 
there was a selection process). The age trends in mental health were less clear, and varied more among the social groups. Large gender differences that widened with age were observed in both France and Switzerland. This finding suggests that there were consistent gender inequalities in both contexts, and that those inequalities tended to accumulate over time. In contrast, no large educational differences in mental health emerged.

The results further showed that the reliability of social networks decreased over age in France, while relationship satisfaction in general was more stable across age groups in Switzerland. Gender and socioeconomic status differences in relational wellbeing were observed in France, but not in Switzerland. The strong reference to the support received from significant others in the SIP questionnaire may explain the decline in relational wellbeing found for older age groups in France. Significant gender differences that increased with age were observed in France for measures of career satisfaction, but not for measures of general job satisfaction in Switzerland. This finding suggests that women tended to have less satisfying professional career opportunities than men, but may not have been less satisfied than men with other aspects of their work. Our failure to find a gender gap in job satisfaction in Switzerland may have also been driven by the selected group of Swiss women who were in full-time work (especially during their childrearing years), as they may have been more career-oriented. Additionally, the low levels of satisfaction observed among French women might be due to a mismatch between the women's professional careers and their expectations, which might have been higher in a country where gender norms are more egalitarian.

To conclude, our results suggest that both gender and socioeconomic inequalities in health and wellbeing are present in France and Switzerland. In particular, we observed significant gender inequalities on a number of wellbeing dimensions in Switzerland, as well as pronounced socioeconomic inequalities in France. Our results on gender in the Swiss context are in line with the traditionalist character of Swiss institutions, which often cause women to be dependent on men. In contrast, the finding of pronounced education inequalities in health in France might be surprising in light of the inclusive public health French system. The crucial factor here might be the much lower prevalence of primary education in Switzerland $(6 \%$, Table A.1) than in France (26\%, Table A.1). On the one hand, due to the low number of observations in the lower educated group, our results might be underestimating the true inequalities in Switzerland because of the large confidence intervals of the estimates. On the other hand, the low prevalence of low education in Switzerland, which is a very rich society, shows that socioeconomic inequalities (at least those based on education) are relatively low in this context. However, this observation also implies that the very few individuals who are disadvantaged in Switzerland are much more deprived than they would be in other contexts, which makes it all the more crucial that studies are conducted to identify the sources and the outcomes of inequalities.

Finally, our findings show that while gender inequalities, when present, tended to accumulate with age, the educational gaps did not seem to diverge over time, but 
were largest in mid-life. This observation suggests that gender inequalities tend to be based on structural disadvantages that grow and accumulate with life events and the ageing process. For instance, the difficulties women face in reconciling family and work and managing career interruptions might have cumulative negative effects that make them more vulnerable than men at older ages. In contrast, socioeconomic inequalities, at least in the two contexts and given the indicators analysed here, seem to be linked to characteristics that matter mostly in mid-life, while they are less relevant for reducing inequalities at older ages.

\section{Acknowledgments}

This research is supported by the Swiss National Science Foundation (SNF).

\section{References}

Arber, S. and H. Cooper 1999. Gender differences in health in later life: the new paradox? Social Science $\mathcal{E}$ Medicine 48(1): 61-76. https://doi.org/10.1016/S0277-9536(98)00289-5 Arrosa, M. L. and N. Gandelman 2016. Happiness decomposition: Female optimism. Journal of Happiness Studies 17(2): 731-756. https://doi.org/10.1007/s10902-015-9618-8

Bambra, C., D. Pope, V. Swami, D. Stanistreet, A. Roskam, A. Kunst and A. Scott-Samuel 2009. Gender, health inequalities and welfare state regimes: A cross-national study of 13 European countries. Journal of Epidemiology and Community Health 63(1): 38-44. https://doi.org/10.1136/jech.2007.070292

Bell, A. and K. Jones 2014. Don't birth cohorts matter? A commentary and simulation exercise on Reither, Hauser, and Yang's (2009) age-period-cohort study of obesity. Social Science $\mathcal{E}$ Medicine 101: 176-180. https://doi.org/10.1016/j.socscimed.2013.09.004

Blanchflower, D. G. and A. J. Oswald 2004. Money, sex and happiness: An empirical study. Scandinavian Journal of Economics 106(3): 393-415. https://doi.org/10.1111/j.03470520.2004.00369.x

Blanchflower, D. G. and A. J. Oswald 2016. Antidepressants and age: A new form of evidence for U-shaped well-being through life. Journal of Economic Behavior and Organization 127: 46-58. https://doi.org/10.1016/j.jebo.2016.04.010

Breton, D., M. Barbieri, N. Belliot, H. d'Albis and M. Mazuy 2019. L'évolution démographique récente de la France: une singularité en Europe? Population 74(4): 409497. https://doi.org/10.3917/popu.1904.0409

Burgard, S. A. and L. Kalousova 2015. Effects of the great recession: Health and wellbeing. Annual Review of Sociology 41: 181-201. https://doi.org/10.1146/annurev-soc-073014112204

Cerci, P. A. and D. Dumludag 2019. Life satisfaction and job satisfaction among university faculty: the impact of working conditions, academic performance and relative income. Social Indicators Research 144(2): 785-806. https://doi.org/10.1007/s11205-018-02059-8 
Cooke, L. P. and J. Baxter 2010. "Families" in international context: comparing institutional effects across western societies. Journal of Marriage and Family 72(3): 516-536. https: //doi.org/10.1111/j.1741-3737.2010.00716.x

Crimmins, E. M. and Y. Saito 2001. Trends in healthy life expectancy in the United States, 1970-1990: gender, racial, and educational differences. Social Science $\mathcal{G}$ Medicine 52(11): 1629-1641. https://doi.org/10.1016/S0277-9536(00)00273-2

Cronin de Chavez, A., K. Backett-Milburn, O. Parry and S. Platt 2005. Understanding and researching wellbeing: Its usage in different disciplines and potential for health research and health promotion. Health education Journal 64(1): 70-87. https://doi.org/10.1177/ 001789690506400108

Cullati, S. 2015. The influence of work-family conflict trajectories on self-rated health trajectories in Switzerland: A life course approach. Social Science $\mathcal{E}$ Medicine 113: 23-33. https://doi.org/10.1016/j.socscimed.2014.04.030

Dahlin, J. and J. Härkönen 2013. Cross-national differences in the gender gap in subjective health in Europe: Does country-level gender equality matter? Social Science $\mathcal{E}$ Medicine 98: 24-28. https://doi.org/10.1016/j.socscimed.2013.08.028

Dannefer, D. 2003. Cumulative advantage/disadvantage and the life course: Cross-fertilizing age and social science theory. The Journals of Gerontology Series B: Psychological Sciences and Social Sciences 58(6): S327-S337. https://doi.org/10.1093/geronb/58.6.S327

De Neve, J. E., N. A. Christakis, J. H. Fowler and B. S. Frey 2012. Genes, economics, and happiness. Journal of Neuroscience, Psychology, and Economics 5(4): 193-211. https://doi.org/10.1037/a0030292

DiPrete, T. A. and G. M. Eirich 2006. Cumulative advantage as a mechanism for inequality: A review of theoretical and empirical developments. Annual Review of Sociology 32: 271-297. https://doi.org/10.1146/annurev.soc.32.061604.123127

Easterlin, R. A. 2001. Life cycle welfare: trends and differences. Journal of Happiness Studies 2(1): 1-12. https://doi.org/10.1023/A:1011504817292

Easterlin, R. A. 2006. Life cycle happiness and its sources: Intersections of psychology, economics, and demography. Journal of Economic Psychology 27(4): 463-482. https: //doi.org/10.1016/j.joep.2006.05.002

Edgerton, J. D., L. W. Roberts and S. von Below 2012. Education and quality of life. In Handbook of social indicators and quality of life research, eds K. Land, A. Michalos and M. Sirgy, 265-296. Springer, Dordrecht. https://doi.org/10.1007/978-94-007-2421-1_12

Eikemo, T. A., M. Huisman, C. Bambra and A. E. Kunst 2008. Health inequalities according to educational level in different welfare regimes: A comparison of 23 European countries. Sociology of Health and Illness 30(4): 565-582. https://doi.org/10.1111/j.1467-9566.2007. 01073.x

Elo, I. 2009. Social class differentials in health and mortality: Patterns and explanations in comparative perspective. Annual Review of Sociology 35: 553-572. https://doi.org/10. 1146/annurev-soc-070308-115929

Esping-Andersen, G. 1990. The three worlds of welfare capitalism. Princeton University Press.

Fagnani, J. 2010. Childcare policies in France: The influence of organizational changes in the workplace. In From child welfare to child well-being, eds S. B. Kamerman, S. Phipps, A. Ben-Arieh, 385-402. Springer, Dordrecht. https://doi.org/10.1007/978-90-481-3377-2_21 
Fernández-Ballesteros, R., M. D. Zamarrón and M. Á. Ruiz 2001. The contribution of socio-demographic and psychosocial factors to life satisfaction. Ageing and Society 21(1): 25-43. https://doi.org/10.1017/S0144686X01008078

Frijters, P. and T. Beatton 2012. The mystery of the U-shaped relationship between happiness and age. Journal of Economic Behavior and Organization 82(2-3): 525-542. https: //doi.org/10.1016/j.jebo.2012.03.008

Hale, L. 2005. Who has time to sleep? Journal of Public Health 27(2): 205-211. https: //doi.org/10.1093/pubmed/fdi004

Huisman, M., A. E. Kunst and J. P. Mackenbach 2003. Socioeconomic inequalities in morbidity among the elderly; a European overview. Social Science E Medicine 57(5): 861-873. https://doi.org/10.1016/S0277-9536(02)00454-9

Huppert, F. A. 2013. The state of Wellbeing Science: Concepts, Measures, Interventions, and Policies. In Wellbeing, ed C. L. Cooper. https://doi.org/10.1002/9781118539415. wbwell036

Huppert, F. A. and T. T. C. So 2013. Flourishing across Europe: Application of a new conceptual framework for defining wellbeing. Social Indicators Research 110(3): 837861. https://doi.org/10.1007/s11205-011-9966-7

Huppert, F. A., N. Marks, A. Clark, J. Siegrist, A. Stutzer, J. Vittersø and M. Wahrendorf 2009. Measuring wellbeing across Europe: Description of the ESS wellbeing module and preliminary findings. Social Indicators Research 91(3): 301-315. https://doi.org/10.1007/ s11205-008-9346-0

Infurna F. J. and S. S. Luthar 2017. The multidimensional nature of resilience to spousal loss. Journal of Personality and Social Psychology 112(6): 926-947. https://psycnet.apa.org/ doi/10.1037/pspp0000095

Keizer, R., P. A. Dykstra and A. R. Poortman 2010. The transition to parenthood and well-being: the impact of partner status and work hour transitions. Journal of Family Psychology 24(4): 429. https://psycnet.apa.org/doi/10.1037/a0020414

Keyes, Corey L. M. 2007. Promoting and protecting mental health as flourishing: A complementary strategy for improving national mental health. American Psychologist 62(2): 95-108. https://psycnet.apa.org/doi/10.1037/0003-066X.62.2.95

Kratz, F. and A. Patzina 2020. Endogenous selection bias and cumulative inequality over the life course: Evidence from educational inequality in subjective well-being. European Sociological Review 36(3): 333-350. https://doi.org/10.1093/esr/jcaa003

Kunst, A. E., J. J. Geurts and J. van den Berg 1995. International variation in socioeconomic inequalities in self reported health. Journal of Epidemiology and Community Health 49(2): 117-123. http://doi.org/10.1136/jech.49.2.117

Lang, I. A., D. J. Llewellyn, R. E. Hubbard, K. M. Langa and D. Melzer 2011. Income and the midlife peak in common mental disorder prevalence. Psychological Medicine 41(7): 1365-1372. http://doi.org/10.1017/S0033291710002060

Lee, C. T., Y. C. Chiang, J. Y. Huang, D. M. Tantoh, O. N. Nfor, J. F. Lee and Y. P. Liaw 2016. Incidence of major depressive disorder: Variation by age and sex in low-income individuals: A population-based 10-year follow-up study. Medicine 95(15). https://doi. org/10.1097\%2FMD.0000000000003110 
Lleras-Muney, A. 2005. The relationship between education and adult mortality in the United States. The Review of Economic Studies 72(1): 189-221. https://doi.org/10.1111/00346527.00329

Loscocco, K. A. and G. Spitze 1990. Working conditions, social support, and the wellbeing of female and male factory workers. Journal of Health and Social Behavior 31(4): 313-327. https://doi.org/10.2307/2136816

Lynch, S. M. 2003. Cohort and life-course patterns in the relationship between education and health: A hierarchical approach. Demography 40(2): 309-331. https://doi.org/10.1353/ dem.2003.0016

Mackenbach, J. P. 2012. The persistence of health inequalities in modern welfare states: The explanation of a paradox. Social Science $\mathcal{E}$ Medicine 75(4): 761-769. https://doi.org/10. 1016/j.socscimed.2012.02.031

Mackenbach, J. P., A. E. Kunst, A. E. Cavelaars, F. Groenhof, J. J. Geurts and EU Working Group on Socioeconomic Inequalities in Health. 1997. Socioeconomic inequalities in morbidity and mortality in western Europe. The Lancet 349(9066): 1655-1659. https: //doi.org/10.1016/S0140-6736(96)07226-1

Madero-Cabib, I. and A. E. Fasang 2016. Gendered work-family life courses and financial well-being in retirement. Advances in Life Course Research 27: 43-60. https://doi.org/10. 1016/j.alcr.2015.11.003

Marmot, M. 2005. Social determinants of health inequalities. The Lancet 365(9464): 10991104. https://doi.org/10.1016/S0140-6736(05)71146-6

Mayer, K. U. 2009. New directions in life course research. Annual Review of Sociology 35: 413-433. https://doi.org/10.1146/annurev.soc.34.040507.134619

McAdams, K. K., R. E. Lucas and M. B. Donnellan 2012. The role of domain satisfaction in explaining the paradoxical association between life satisfaction and age. Social Indicators Research 109(2): 295-303. https://doi.org/10.1007/s11205-011-9903-9

McDonough, P., D. Worts, C. Booker, A. McMunn and A. Sacker 2015. Cumulative disadvantage, employment-marriage, and health inequalities among American and British mothers. Advances in Life Course Research 25: 49-66. https://doi.org/10.1016/j.alcr.2015. 05.004

McPherson, M., L. Smith-Lovin and M. E. Brashears 2006. Social isolation in America: Changes in core discussion networks over two decades. American Sociological Review 71(3): 353-375. https://doi.org/10.1177\%2F000312240607100301

Melchior, M., A. Caspi, B. Milne, A. Danese, R. Poulton and T. Moffitt 2007. Work stress precipitates depression and anxiety in young, working women and men. Psychological Medicine 37: 1119-1129. https://doi.org/10.1017\%2FS0033291707000414

Miilunpalo, S., I. Vuori, P. Oja, M. Pasanen and H. Urponen 1997. Self-rated health status as a health measure: The predictive value of self-reported health status on the use of physician services and on mortality in the working-age population. Journal of Clinical Epidemiology 50(5): 517-528. https://doi.org/10.1016/S0895-4356(97)00045-0

Mirowsky, J. and C. E. Ross 1998. Education, personal control, lifestyle and health: A human capital hypothesis. Research on Aging 20(4): 415-449. https://doi.org/10.1177\% 2F0164027598204003 
Mirowsky, J. and C. E. Ross 2005. Education, cumulative advantage, and health. Ageing International 30(1): 27-62. https://doi.org/10.1007/BF02681006

Mirowsky, J. and C. E. Ross 2007. Life course trajectories of perceived control and their relationship to education. American Journal of Sociology 112(5): 1339-1382. https: //doi.org/10.1086/511800

Needham, B. and T. D. Hill 2010. Do gender differences in mental health contribute to gender differences in physical health? Social Science and Medicine 71(8): 1472-1479. https://doi.org/10.1016/j.socscimed.2010.07.016

Oksuzyan, A., Dańko, M. J., J. Caputo, D. Jasilionis and V. M. Shkolnikov 2019. Is the story about sensitive women and stoical men true? Gender differences in health after adjustment for reporting behavior. Social Science $\mathcal{E}$ Medicine 228: 41-50. https://doi.org/10.1016/j. socscimed.2019.03.002

Oncini, F. and R. Guetto 2018. Cultural capital and gender differences in health behaviours: A study on eating, smoking and drinking patterns. Health Sociology Review 27(1): 15-30. https://doi.org/10.1080/14461242.2017.1321493

Pailhé, A., C. Rossier and L. Toulemon 2008. French family policy: long tradition and diversified measures. Vienna Yearbook of Population Research 2008: 149-164. https: //doi.org/10.1553/populationyearbook2008s149

Pampel, F. C., P. M. Krueger and J. T. Denney 2010. Socioeconomic disparities in health behaviors. Annual Review of Sociology 36: 349-370. https://doi.org/10.1146/annurev.soc. 012809.102529

Peters, R. 2014. La discrimination fiscal entre les couples mariés et non mariés dans les cantons et à la Confédération, Département Fédéral des Finances, Suisse.

Pinquart, M. and S. Sörensen 2001. Gender differences in self-concept and psychological wellbeing in old age: A meta-analysis. The Journals of Gerontology Series B: Psychological sciences and social sciences 56(4): 195-213. https://doi.org/10.1093/geronb/56.4.P195

Pollard, E. L. and P. D. Lee 2003. Child wellbeing: A systematic review of the literature. Social Indicators Research 61(1): 59-78. https://doi.org/10.1023/A:1021284215801

Prus, S. G. 2004. A life course perspective on the relationship between socio-economic status and health: Testing the divergence hypothesis. Canadian Journal on Aging/La Revue canadienne du vieillissement 23(5): 145-153. http://doi.org/10.1353/cja.2005.0040

Pursey, K., T. L. Burrows, P. Stanwell and C. E. Collins 2014. How accurate is web-based self-reported height, weight, and body mass index in young adults? Journal of medical Internet research 16(1): e4. https://doi.org/10.2196/jmir.2909

Ross, C. E. and M. Van Willigen 1997. Education and the subjective quality of life. Journal of Health and Social Behavior 38(3): 275-297. https://doi.org/10.2307/2955371

Ross, C. E. and C. Wu 1995. The links between education and health. American Sociological Review 60(5): 719-745. https://doi.org/10.2307/2096319

Ryff, C. D. and C. L. M. Keyes 1995. The structure of psychological wellbeing revisited. Journal of Personality and Social Psychology 69(4): 719-727. https://psycnet.apa.org/doi/ 10.1037/0022-3514.69.4.719

Spitzer, S. and D. Weber 2019. Reporting biases in self-assessed physical and cognitive health status of older Europeans. PLoS ONE 14(10): e0223526. https://doi.org/10.1371/ journal.pone. 0223526 
Subramanian, S. V., D. Kim and I. Kawachi 2005. Covariation in the socioeconomic determinants of self-rated health and happiness: a multivariate multilevel analysis of individuals and communities in the USA. Journal of Epidemiology and Community Health 59(8): 613. http://doi.org/10.1136/jech.2004.025742

Townsend, P. and N. Davidson (eds). 1982. Inequalities in Health: The Black Report. Harmondsworth: Penguin.

Troxel, W. M., D. J. Buysse, K. A. Matthews, H. M. Kravitz, J. T. Bromberger, M. Sowers and M. H. Hall 2010. Marital/cohabitation status and history in relation to sleep in midlife women. Sleep 33(7): 973-981. https://doi.org/10.1093/sleep/33.7.973

Ulloa, B. F. L., V. Møller, and A. Sousa-Poza 2013. How does subjective well-being evolve with age? A literature review. Journal of Population Ageing 6(3): 227-246. https://doi. org/10.1007/s12062-013-9085-0

Von dem Knesebeck, O., P. E. Verde and N. Dragano 2006. Education and health in 22 European countries. Social Science $\mathcal{E}$ Medicine 63(5): 1344-1351. https://doi.org/10. 1016/j.socscimed.2006.03.043

Walker, A. 2005. A European perspective on quality of life in old age. European Journal of Ageing 2: 2-12. https://doi.org/10.1007/s10433-005-0500-0

Wall, K. and A. Escobedo 2013. Parental leave policies, gender equity and family well-being in Europe: A comparative perspective. In Family Well-Being, ed A. Moreno Minguez, 103-129. Dordrecht: Springer. https://doi.org/10.1007/978-94-007-4354-0_6

Wheaton, B. 1980. The sociogenesis of psychological disorder: An attributional theory. Journal of Health and Social Behavior 21: 100-124. https://doi.org/10.2307/2136730

Widmer, E., R. Levy, A. Pollien, R. Hammer and J. A. Gauthier 2003. Entre standardisation, individualisation et sexuation: une analyse des trajectoires personnelles en Suisse. Revue Suisse de Sociologie 29: 35-67.

Yang, Y. 2008. Social inequalities in happiness in the United States, 1972 to 2004: An age-period-cohort analysis. American Sociological Review 73(2): 204-226. https://doi. org/10.1177\%2F000312240807300202 


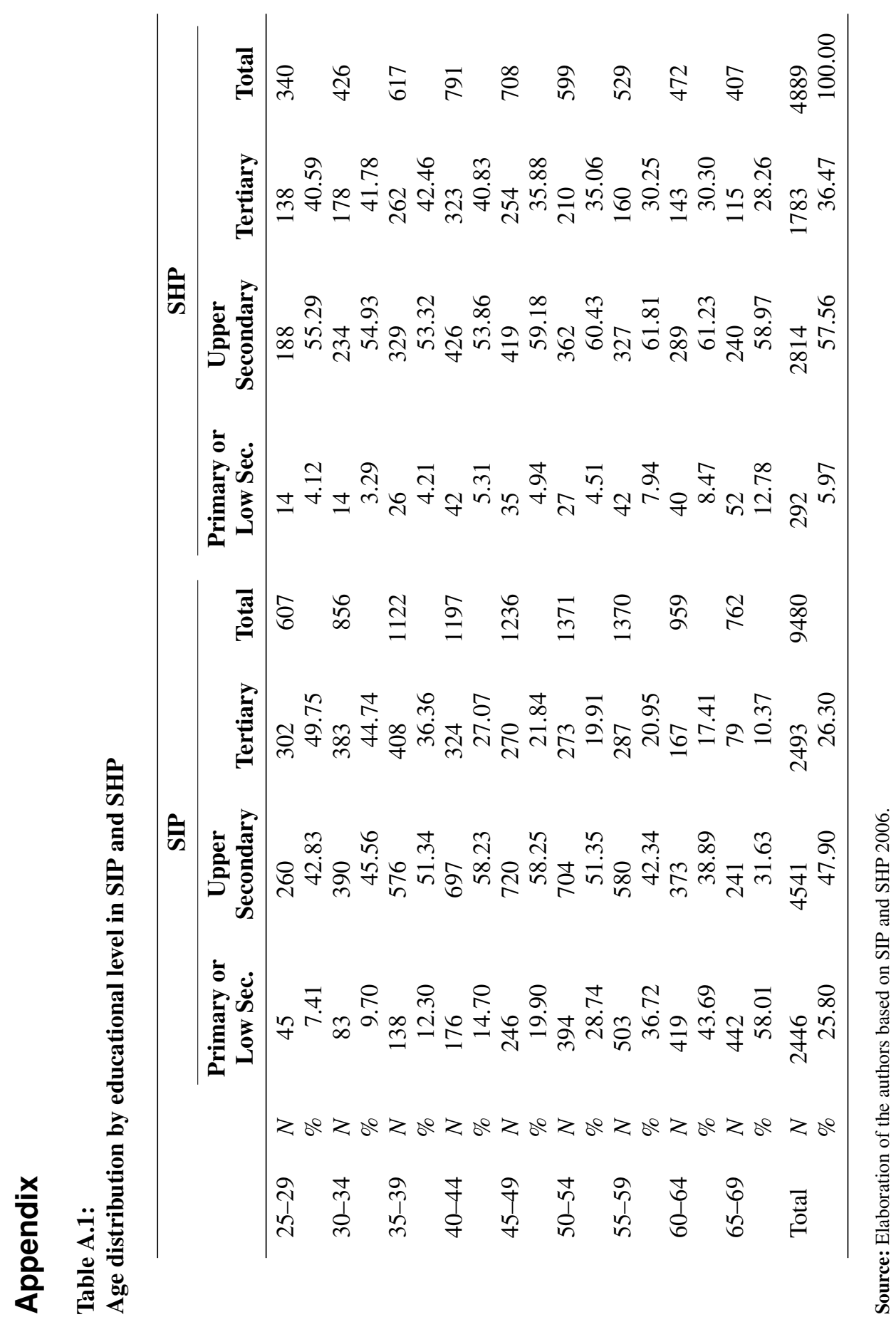




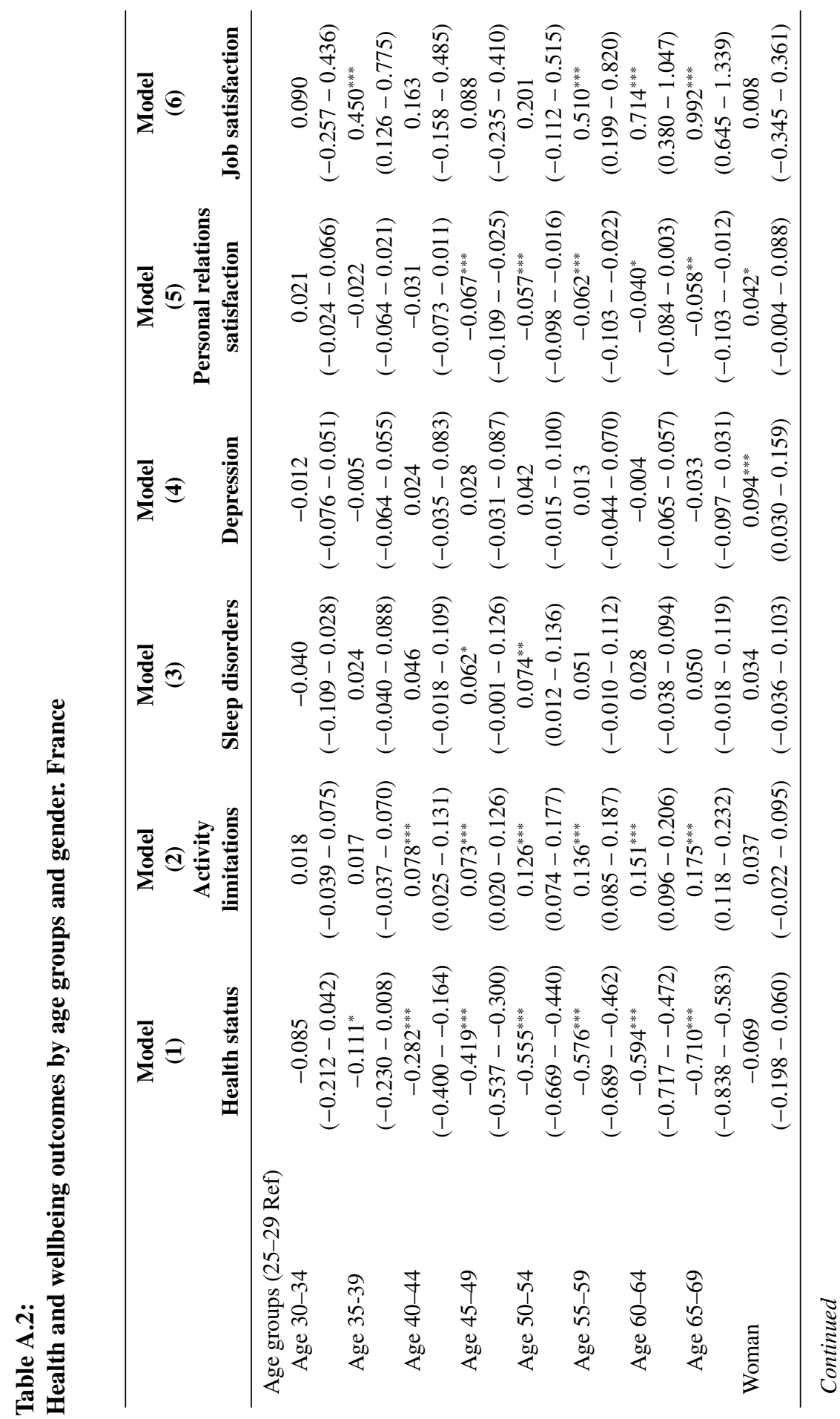




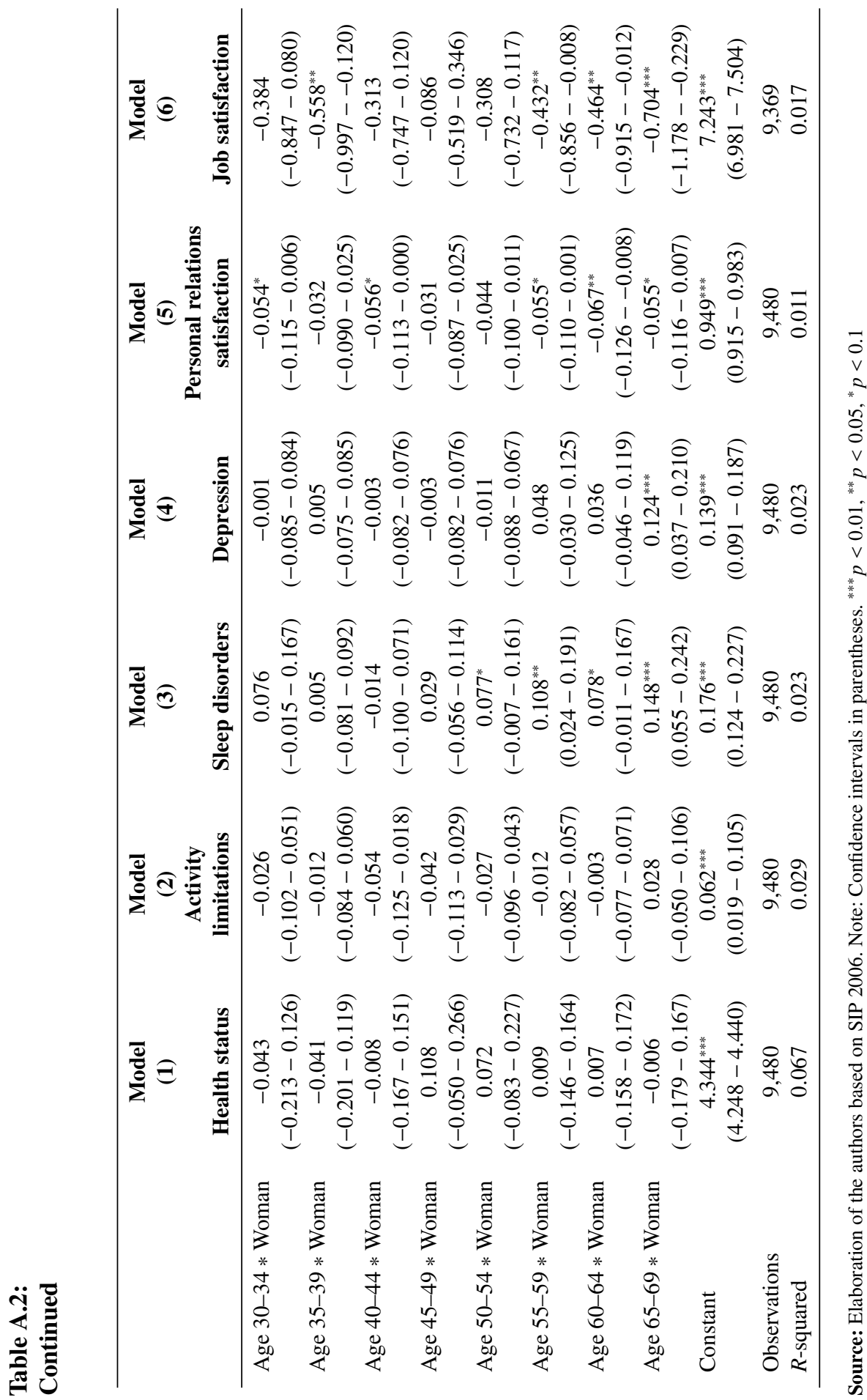




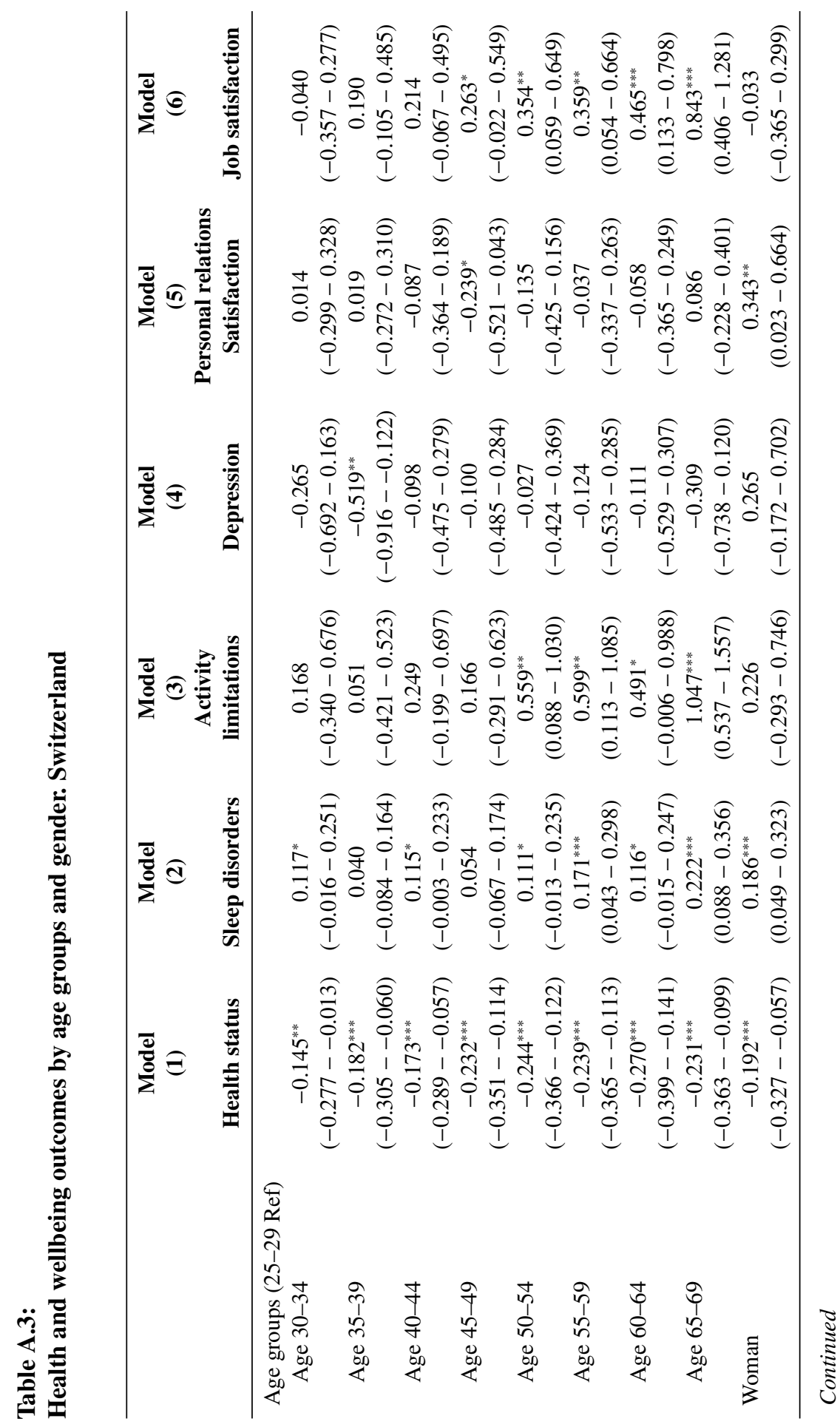




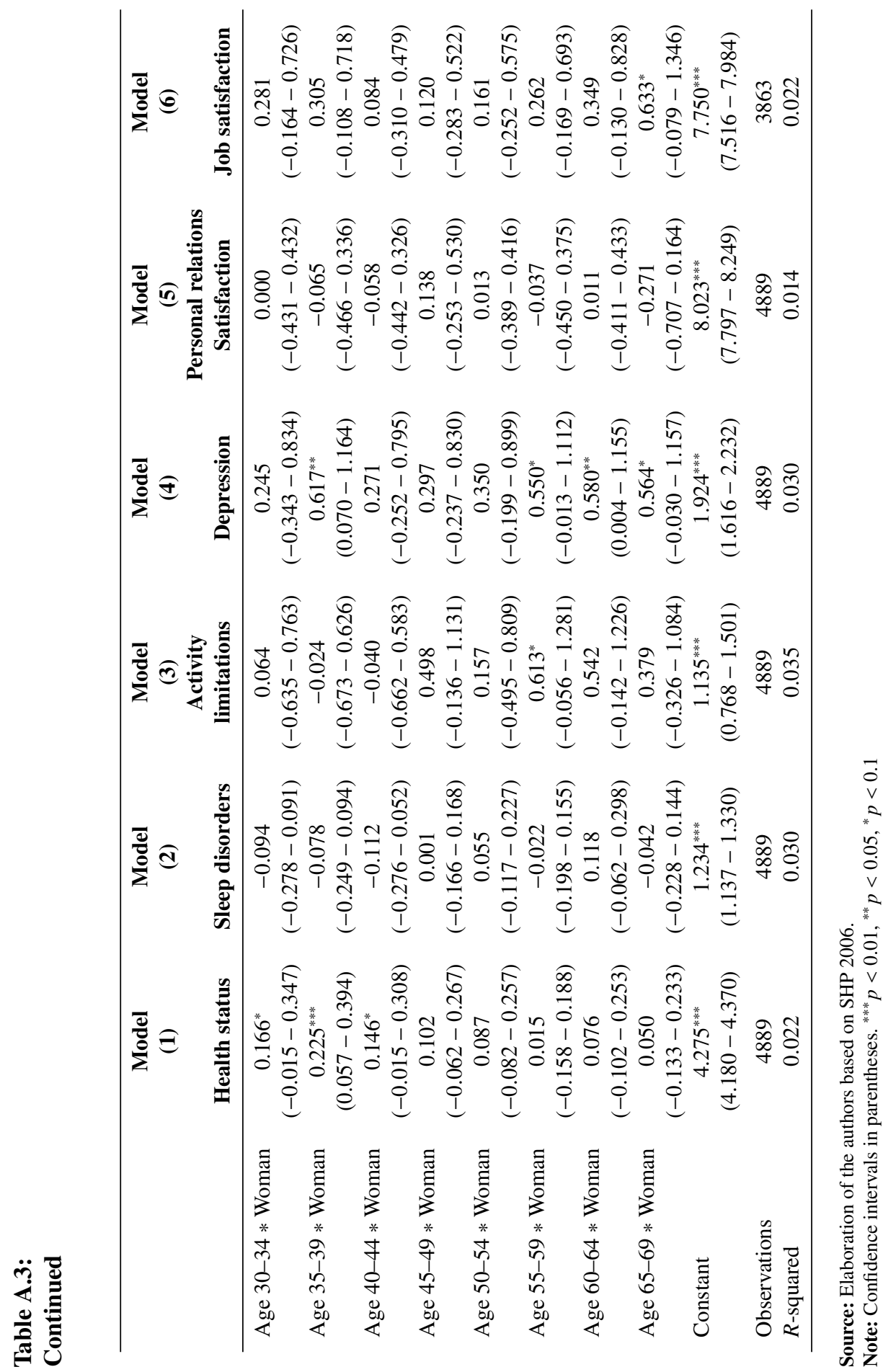




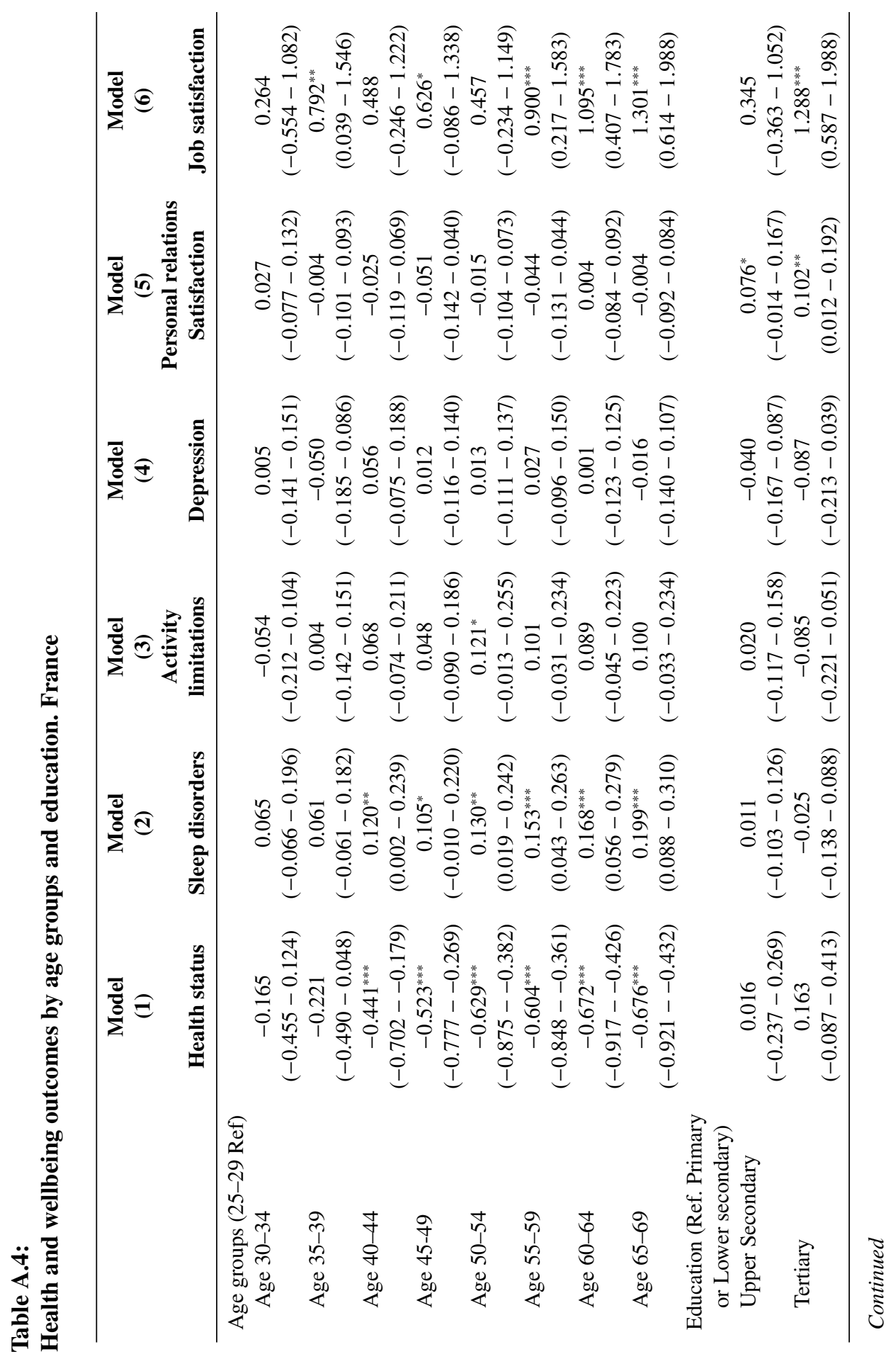




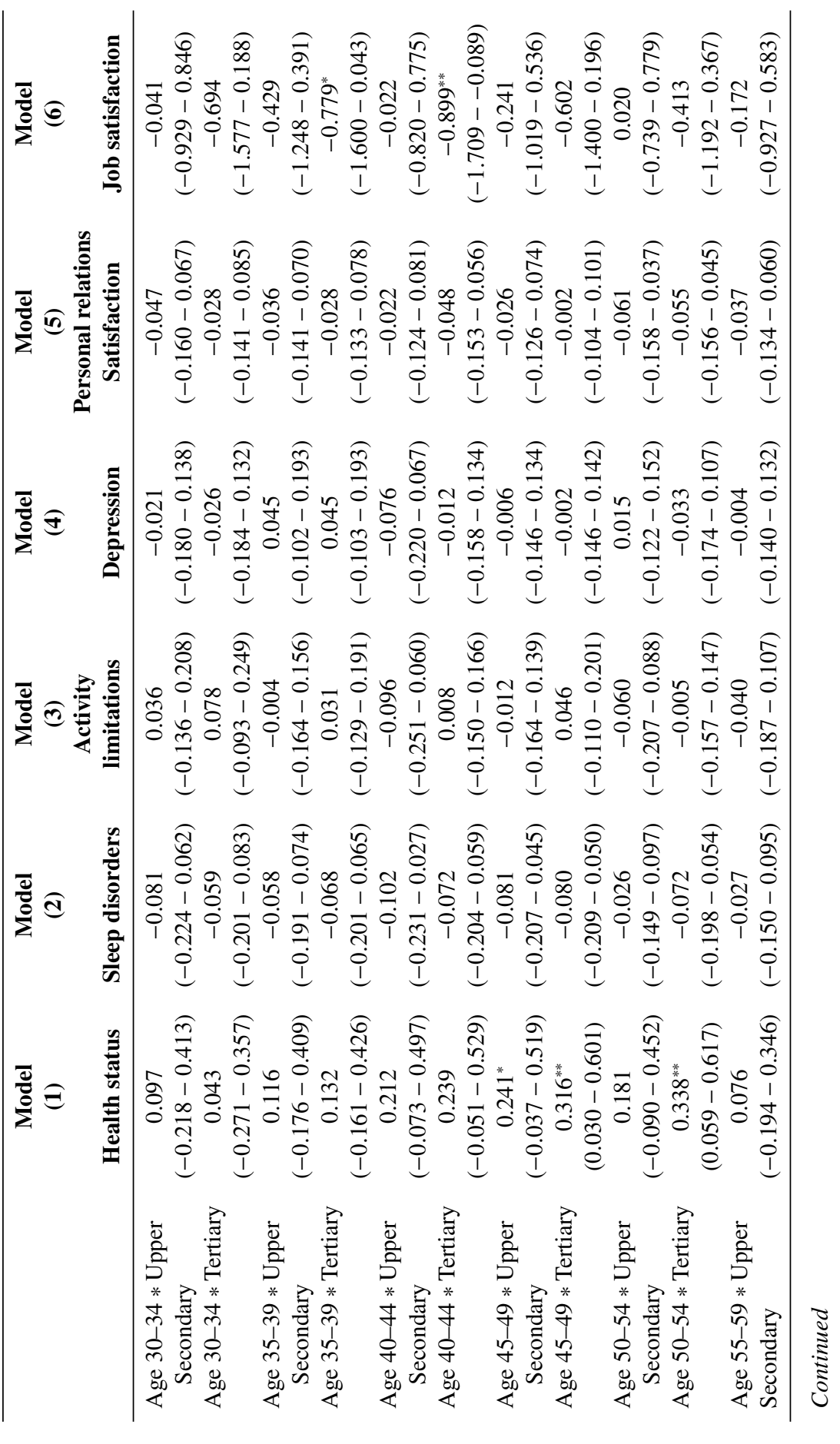




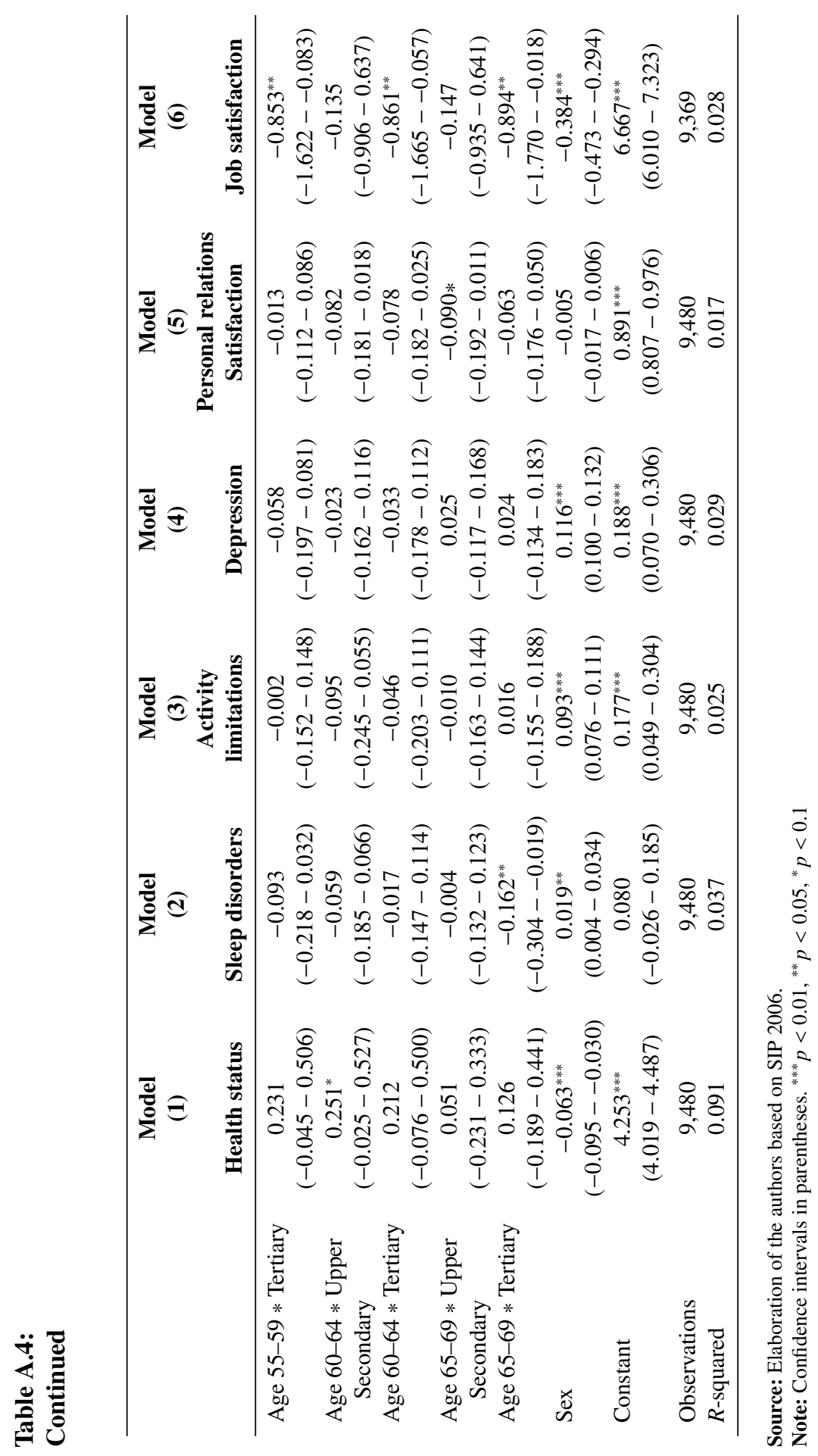




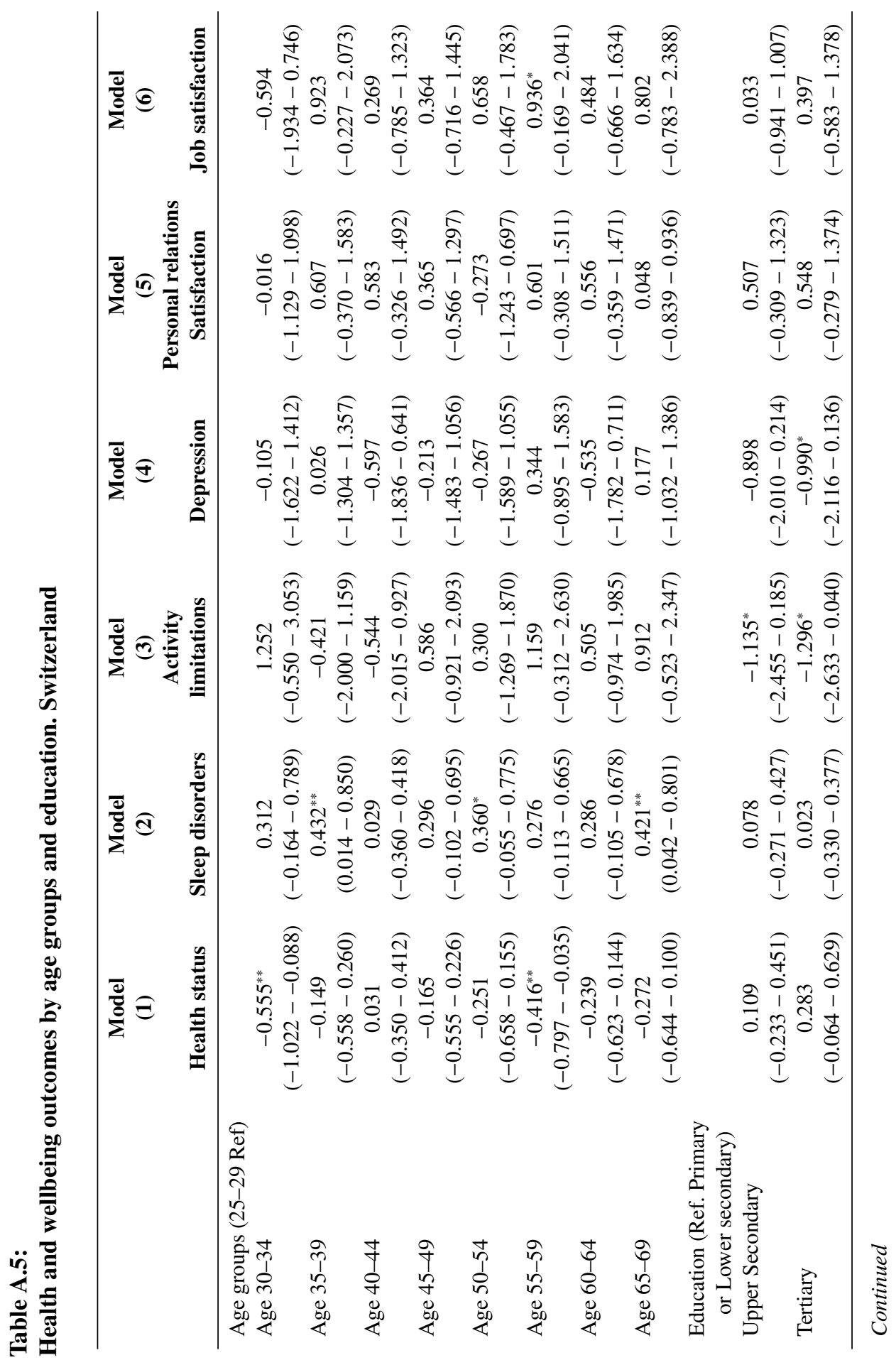




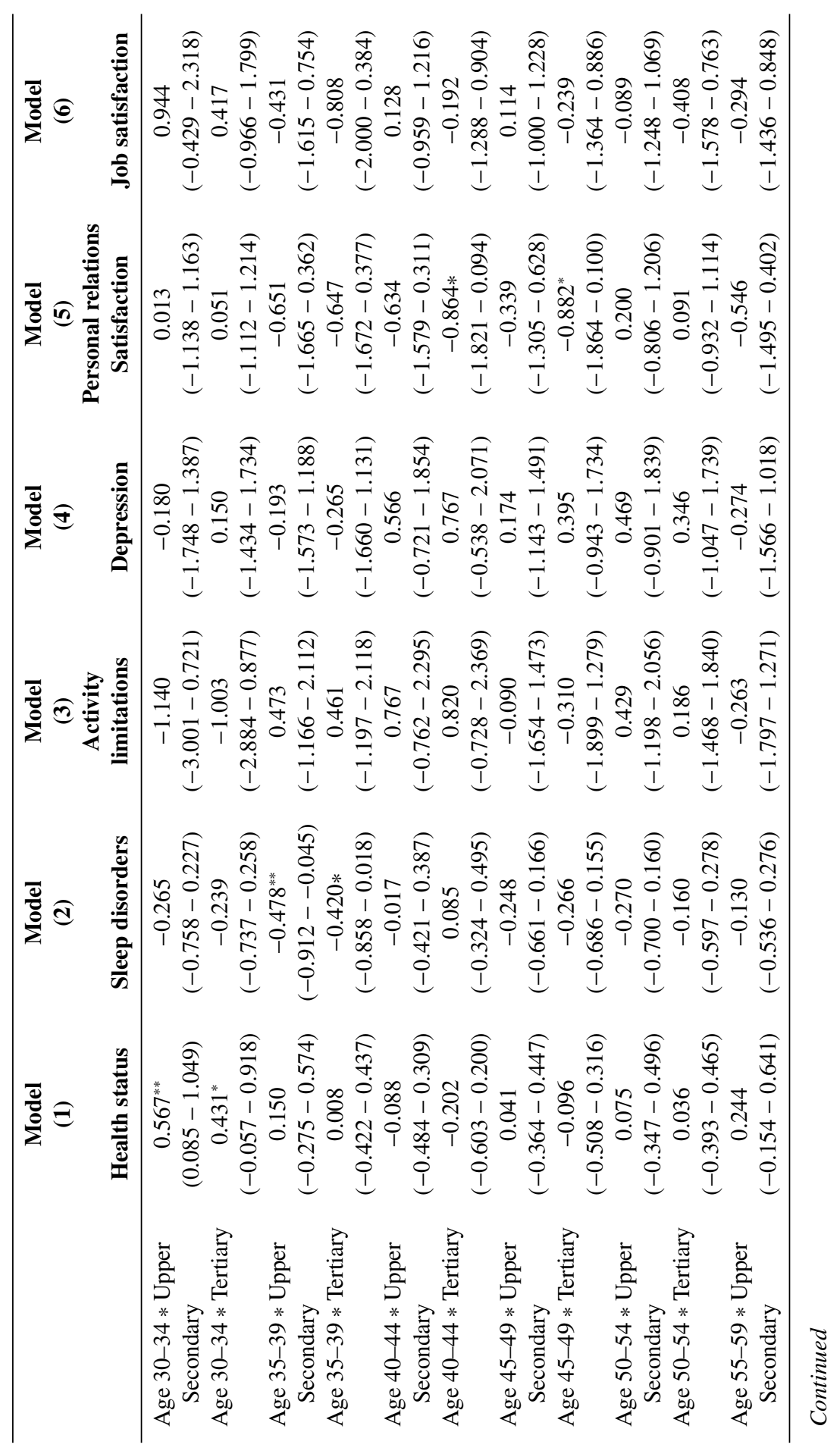




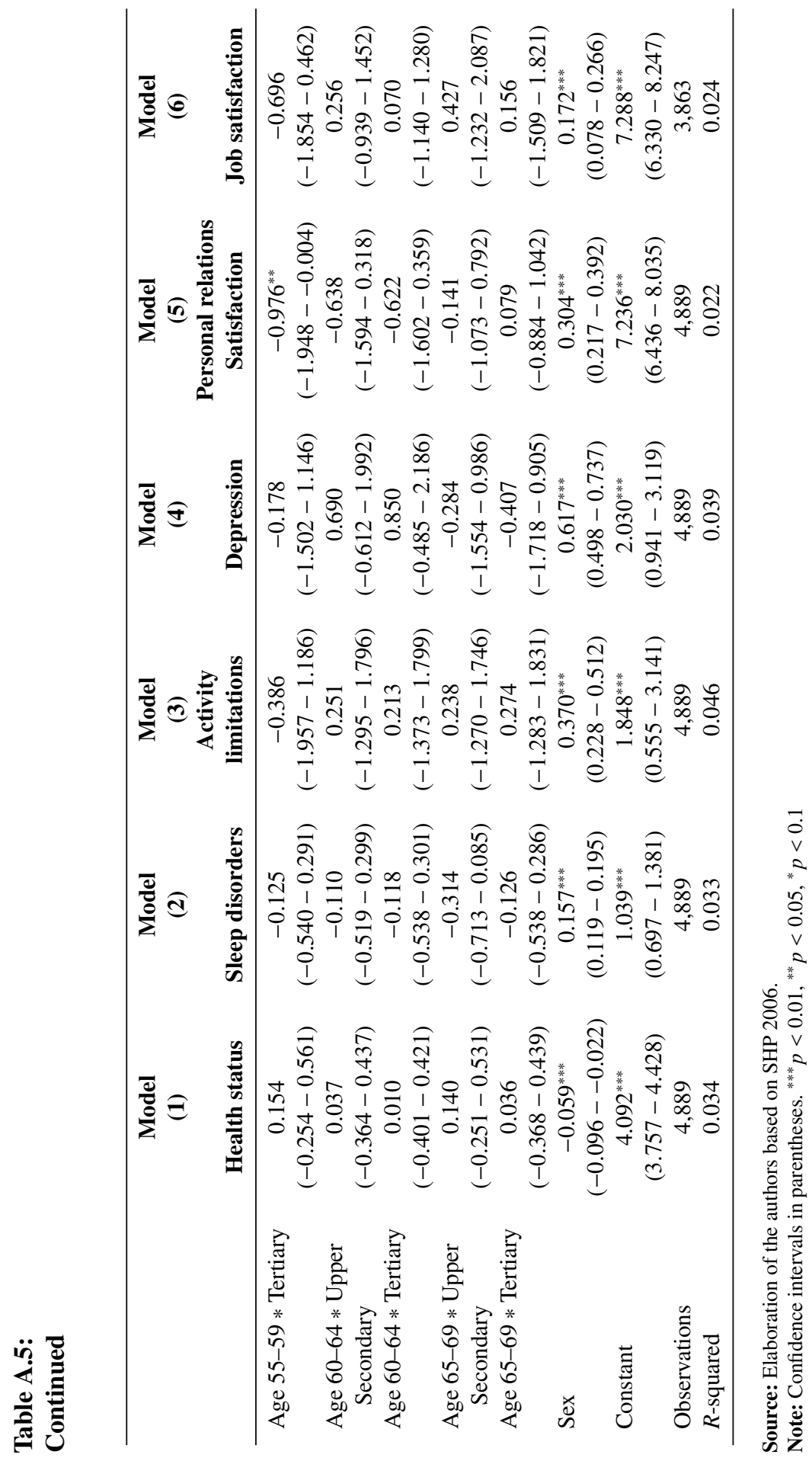


Open Access This article is published under the terms of the Creative Commons Attribution 4.0 International License (https://creativecommons.org/licenses/by/4.0/) that allows the sharing, use and adaptation in any medium, provided that the user gives appropriate credit, provides a link to the license, and indicates if changes were made. 